\title{
SAXS-WAXS monitoring of the amyloid fibril assembly of a hormone peptide analogue upon $\mathrm{pH}$ change.
}

\author{
Frédéric Gobeaux ${ }^{1,}{ }^{*}$, David Carrière ${ }^{1}$, Frank Wien ${ }^{2}$, Rajeev Dattani ${ }^{3}$
}

\author{
1 Université Paris-Saclay, CEA, CNRS, NIMBE, 91190 Gif-sur-Yvette, France \\ 2 SOLEIL Synchrotron, Saint Aubin, France \\ ${ }^{3}$ ESRF - The European Synchrotron, 71 avenue des Martyrs, 38000 Grenoble, France \\ * frederic.gobeaux@cea.fr
}

\section{TOC graphic}

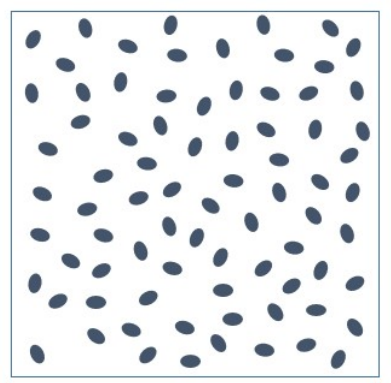

Peptide monomers

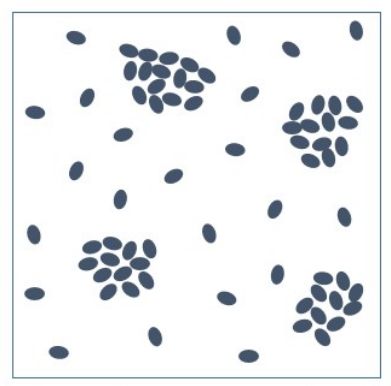

Amorphous aggregates

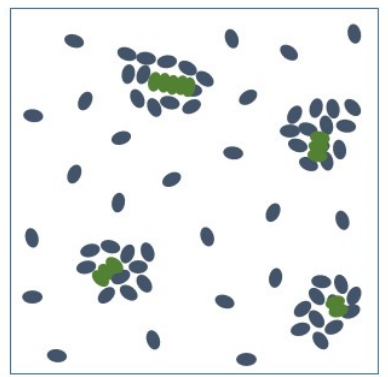

$\beta$-sheets nucleate in amorphous aggregates

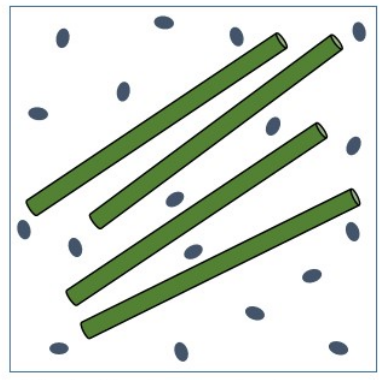

Fibrils (in dynamical equilibrium with monomers)

\section{Abstract}

Amyloid structures represent one of the most widespread and stable protein folding in nature. This particular folding can be either beneficial or detrimental to its host organism depending on the conditions and places of aggregation. Consequently, the space and time control of their formation mechanisms of amyloid fibril formation is crucial. In the present work, we have investigated the assembly properties of the terlipressin (TLP), a peptide analogue of the vasopressin hormone that is known - like many other peptide hormones - to be stored under the form of reversible amyloid fibrils, which suggests a finely tuned aggregation process. In particular, the assembly kinetics has been monitored by small and wide-angle $\mathrm{x}$-ray scattering (SAXS-WAXS). In combination with circular dichroism, ATR-FTIR and cryoTEM characterization, this analysis reveals that the TLP assembly goes through the formation of onpathway transitory amorphous aggregates in which the amyloid fibrils nucleate. At the end of the process, the "amyloid phase" (i.e., the fibrils) is in dynamic equilibrium with the liquid phase (peptide monomers). The proportion between the two phases depends on the $\mathrm{pH}$ and peptide concentration. Finally, the reversibility of the assembly is assessed. 
Keyword: peptide; aggregation; functional amyloid; SAXS; in-situ kinetics; $p H$

\section{Introduction}

Neuropeptides and peptide hormones fibrils now constitute a well-known example of a physiological use of amyloid assemblies. Amyloid assemblies have for a long time only been associated with protein misfolding leading to neurodegenerative diseases ${ }^{1}$ - and mainly continue to be so. ${ }^{2}$ Thus, by contrast, amyloid structures providing a gain to their host have been termed "functional amyloids". ${ }^{3}$ It appears that functional amyloids are ubiquitous in the biological realm and that the functions fulfilled by these structures are very eclectic. ${ }^{4}$ In the case of neuropeptides and peptide hormones, amyloid structures serve as a highly concentrated/condensed storage means in secretory cells.5,6 Indeed, peptide hormones have been found to be stored in dense-core vesicles under an amyloid-like form. ${ }^{5}$ Such long-term storage allows hormones to be secreted faster than they are synthesized. Indeed, peptide hormones are not continuously secreted at a rate determined by the rate of protein synthesis (as in the constitutive secretory pathway) but are released as pulsatile bursts in response to a stimulus (regulated secretory pathway).7-9

Nevertheless, this sequence-specific aggregation propensity remains equivocal since in the absence of proper control it can lead to pathological aggregation outside secretory

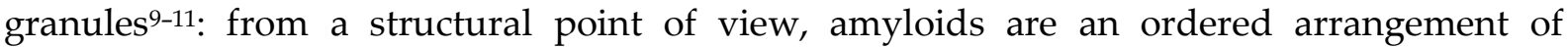
thousands of monomers (e.g. proteins or peptides) which relies on the formation of cross- $\beta$ sheet motifs through repeated intermolecular H-bonds. Their formation typically follows a sigmoidal increase of amyloid mass, with three characteristic kinetic stages: a lag phase, a growth phase and a final plateau regime. This profile is generally explained by a nucleationdependent polymerization mechanism ${ }^{12,13}$ : nucleation of amyloid structure is supposed to occur during the lag phase, elongation of the fibrils by monomer addition during the growth phase and finally the system reach an equilibrium (plateau). Of course, this is a simplified scheme. In reality, mechanism is often more complex and the nucleated conformation conversion mechanism was proposed to account for the formation of "structurally fluid oligomeric complexes".14 The most debated step is nucleation, which involves (i) conformational changes of the monomer and (ii) intermolecular interactions resulting in various aggregated intermediates: more or less organized oligomers, prefibrillar aggregates, proper amyloid nuclei, etc... Further, fragmentation can occur during the elongation phase 
giving rise to secondary nucleation. Finally, maturation of the fibrils can also happen after equilibrium has been reached. In addition to other techniques (ThT fluorescence measurements, circular dichroism, microscopies, NMR...), time-resolved SAXS experiment recently brought very detailed insight in the chain of events leading to the formation of different types of amyloid fibrils ${ }^{15-19}$, showing the formation of oligomeric species or protofibrils.

The key feature of functional hormone amyloids is the reversibility of the aggregation allowing the secretion of bioactive monomers. This property was thus readily exploited by researchers to design devices enabling to control the delivery of peptide drugs ${ }^{20-24}$, although it only represents a handful of examples. The "easy" reversibility is thus a distinguishing mark differentiating hormone amyloids from others types of amyloids, especially pathogenic ones, which are commonly described as stable and insoluble. ${ }^{25}$, Moreover, several studies on peptide hormone analogues have demonstrated that these amyloid assemblies are in dynamic equilibrium with monomers. ${ }^{26-28}$ Such characteristics are expected to play a significant role in the assembly mechanism. Whether it be in a pathological context or in a functional context, it is crucial to understand the mechanisms leading to amyloid fibrils. Most mechanistic studies were carried out to elucidate pathological aggregation, and thus focused on prion proteins, $\mathrm{A} \beta-(1-42)$, insulin and calcitonin. This generally involves using denaturing conditions leading to irreversible* and often polymorphic assemblies. These studies often report the formation of oligomers that are commonly held responsible for amyloid toxicity. Likewise, the polymorphism stems from kinetically trapped intermediates ("off-pathway"). Consequently, the mechanisms derived from the study of thermodynamically controlled system where assemblies are in dynamic equilibrium with monomers might differ significantly. For example, we hypothesize that functional amyloid assembly mechanism could escape the formation of such transient, toxic oligomeric species and that the resulting fibrils exhibit little polymorphism. So far, only a few studies have focused on the assembly dynamics of reversible functional amyloids and none report the formation of such oligomers, but rather a sequence of well-defined transitions. ${ }^{26,33,34,28}$

\footnotetext{
${ }^{*}$ Nevertheless, the complete irreversibility of amyloid assemblies has been recently reassessed ${ }^{29-32}$
} 
In this paper, we study the self-assembling properties of terlipressin (tryglycil-lysine vasopressin, referred to as TLP from then on), a synthetic analogue of vasopressin. It is a potent vasopressor that is a useful therapeutic agent in the treatment of cardiac arrest, septic and catecholamine-resistant shock and oesophageal variceal haemorrhage. ${ }^{35}$ A virtual screening study has also recently predicted through docking simulation that TLP (among other hormone peptides) could bind the SARS-CoV-2 spike protein. ${ }^{36}$ This vasopressin analog has a longer duration of action and a better safety profile than the parent compound. TLP is a 12 aminoacid cyclic peptide (Figure 1A). TLP possesses two aromatic residues side-by-side (Tyr and Phe) whose hydrophobicity is compensated by the hydrophilic lysine residue in position 11 that come with acetate as a counterion. The C-terminal is protected by amidification. The net charge of the peptide ranges from +2 at acidic $\mathrm{pH}$ levels to -1 at basic ones (see Figure $1 \mathrm{~B}$ ). Overall, this sequence is very similar to that of vasopressin, but also of oxytocin (see Figure S1 in SI). TLP mainly differs from these natural peptides by the N-tryglycil residue which is cleaved by endothelial peptidases, releasing the active lysine-vasopressin ${ }^{35}$ and by the substitution of Lysine (Lys) for arginine at position 8 of the vasopressin molecule (although lys-vasopressin also exists in vivo, notably in pigs).

As previous studies have shown on comparable hormone-like peptides $5,24,28,34,37-41$, these features (cyclic structure, balance between a aromaticity and ionic charges) suggest a good propensity to self-assemble in amyloid-like structure. And indeed, Beuret et al. have recently demonstrated through Pro/Gly scans and truncations of the provasopressin 1-75 sequence that the nonapeptide vasopressin sequence is both necessary and sufficient to prompt the aggregation of a polypeptide chain. ${ }^{11}$ In the following, we extensively characterize concentrated solutions of TLP as a function of $\mathrm{pH}$ and of time with ATR-FTIR and small and wide angle x-ray scattering (SAXS-WAXS). We observe that self-assembly propensity is very dependent on $\mathrm{pH}$. We also characterize the induction and growth phase of TLP fibrils assembly with combined SAXS-WAXS and demonstrate that the assembly do not go through the formation of intermediate oligomeric species but rather through the formation of amorphous aggregates in which the amyloid fibrils nucleate, recalling non-classical crystallization mechanisms. Since these amyloid gels are reversible, the controlled, slow release of TLP from an amyloid gel depot could be envisioned to replace continuous infusion of low-dose terlipressin ${ }^{42}$ as it was suggested for a family of short- and long-acting analogs of gonadotropin-releasing hormone $(\mathrm{GnRH}) \cdot{ }^{21}$ 


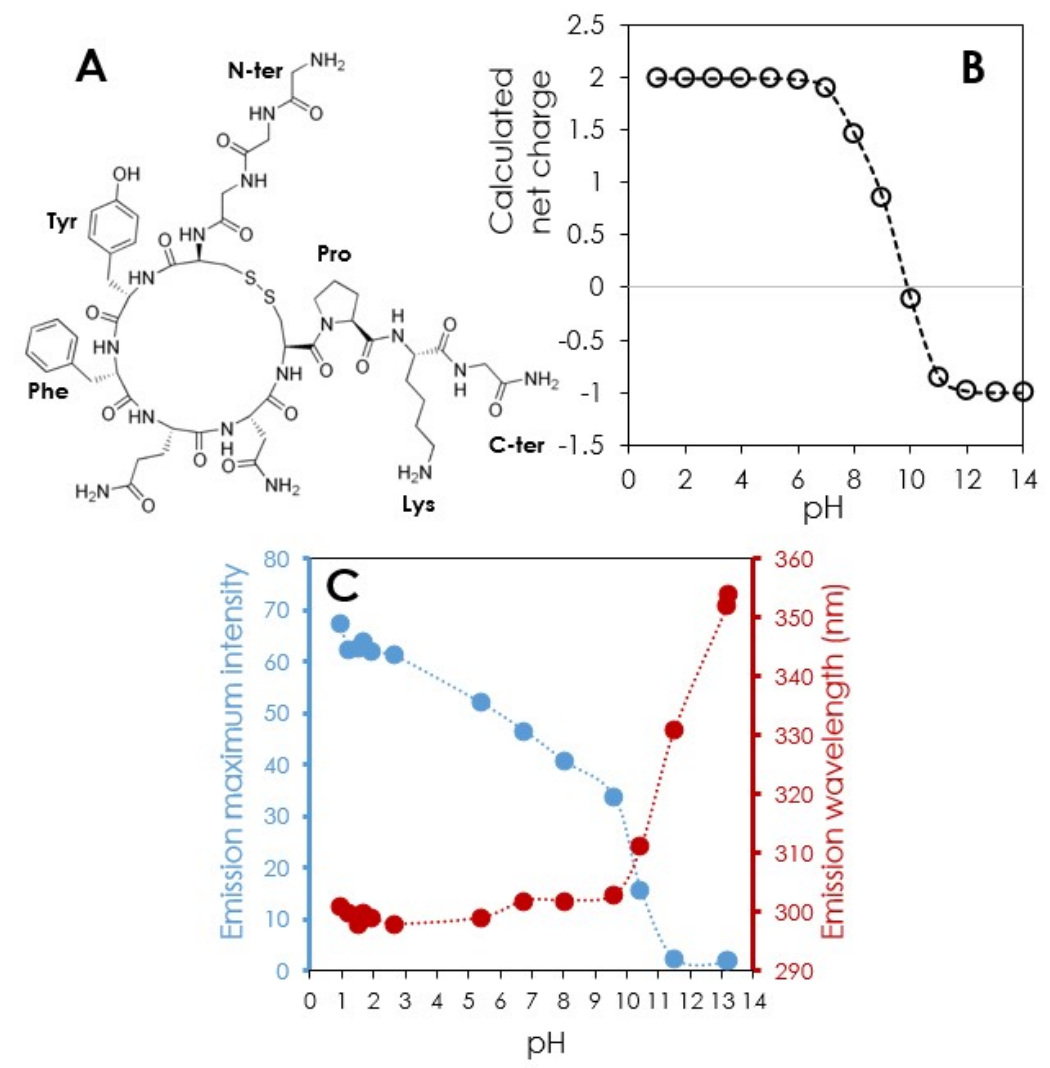

Figure 1 : A) Developed formula of terlipressin peptide (TLP). B) Calculated net charge of the TLP peptide as a function of $\mathrm{pH}$. C) Fluorimetric titration of $1 \mathrm{mg} / \mathrm{ml}$ TLP solution ranging from $\mathrm{pH} 2.67$ to $\mathrm{pH} 13.21$ (blue diamonds). Plot of the wavelength of the maximum of emission as a function of $\mathrm{pH}$ (red squares).

\section{Results}

\section{Terlipressin assembly as a function of $\mathrm{pH}$}

As mentioned in the introduction, one of the interesting features of TLP is the presence of a tyrosine in its amino acid sequence, which makes TLP intrinsically fluorescent and sensitive to $\mathrm{pH}$. A fluorescence titration of $1 \mathrm{mg} / \mathrm{ml}$ solutions of TLP is presented in Figure 1C. A quench of the fluorescence emission is observed as $\mathrm{pH}$ increases with a steep drop at $\mathrm{pH}$ 10-11. In the same $\mathrm{pH}$ range, a strong shift of fluorescence emission maximum from $300 \mathrm{~nm}$ to $350 \mathrm{~nm}$ occurs. This quenching is mainly attributable to the deprotonation of the phenol group ${ }^{43}$ and cannot therefore be used as a marker of peptide aggregation. ${ }^{28}$ Nevertheless, visual inspection of the sample can give a first sense of the TLP propensity to self-assemble.

At acidic $\mathrm{pH}$, the TLP peptide powder is very easily soluble thanks to its +2 positive net charge, and a clear liquid solution is obtained at concentration up to $10 \% \mathrm{w} / \mathrm{w}$. At neutral and mildly basic $\mathrm{pH}$ levels, the solutions become viscous when the concentration reaches a few $\% \mathrm{w} / \mathrm{w}$, and even form a gel at $\mathrm{pH}$ levels higher than 8 . Observed between cross-polaroids, 
these gels exhibit birefringence, indicating a mesostructural anisotropy (Figure 2A-B). At $10 \% \mathrm{w} / \mathrm{w}$ basic gels may also become turbid (Figure 2B).

A first insight in the sequence of phases and changes in conformation of TLP during assembly can be obtained by assessing TLP solutions with synchrotron radiation circular dichroism (SRCD) measurements. Typically, negative bands at $200 \mathrm{~nm}$ are associated with disordered ("random coil") conformation while a shift towards $220 \mathrm{~nm}$ and more pertains to the formation of $\beta$-sheets. ${ }^{44}$ The Figure 2C compares the SRCD spectra for two 10\% TLP solutions: one is liquid (solubilized in water, red trace, $\mathrm{pH}=7.2$ ) and the other is a gel (solubilized in $0.2 \mathrm{M} \mathrm{NaOH}$, blue trace, $\mathrm{pH}=13$ ). In both cases, the spectrum is rather simple and mainly presents a single, slightly asymmetric, negative band whose minimum ranges from 200 in the liquid solution to $224 \mathrm{~nm}$ in the gel solution. A similar band was observed by Hernández et al. ${ }^{45}$ in the CD spectrum of somatostatine-14, a comparable amyloid-prone cyclic peptide hormone, in water (at $0.04 \% \mathrm{w} / \mathrm{w})$. They interpreted it as a sign of the predominance of randomly structured conformers in solution. The shift of the negative band upon gelification towards $224 \mathrm{~nm}$ is indicative of the formation of $\beta$-sheets. This negative peak is usually associated with a positive band at lower wavelength. This second peak cannot be detected here because of the saturation of the dynode voltage due to the very high concentration used. 

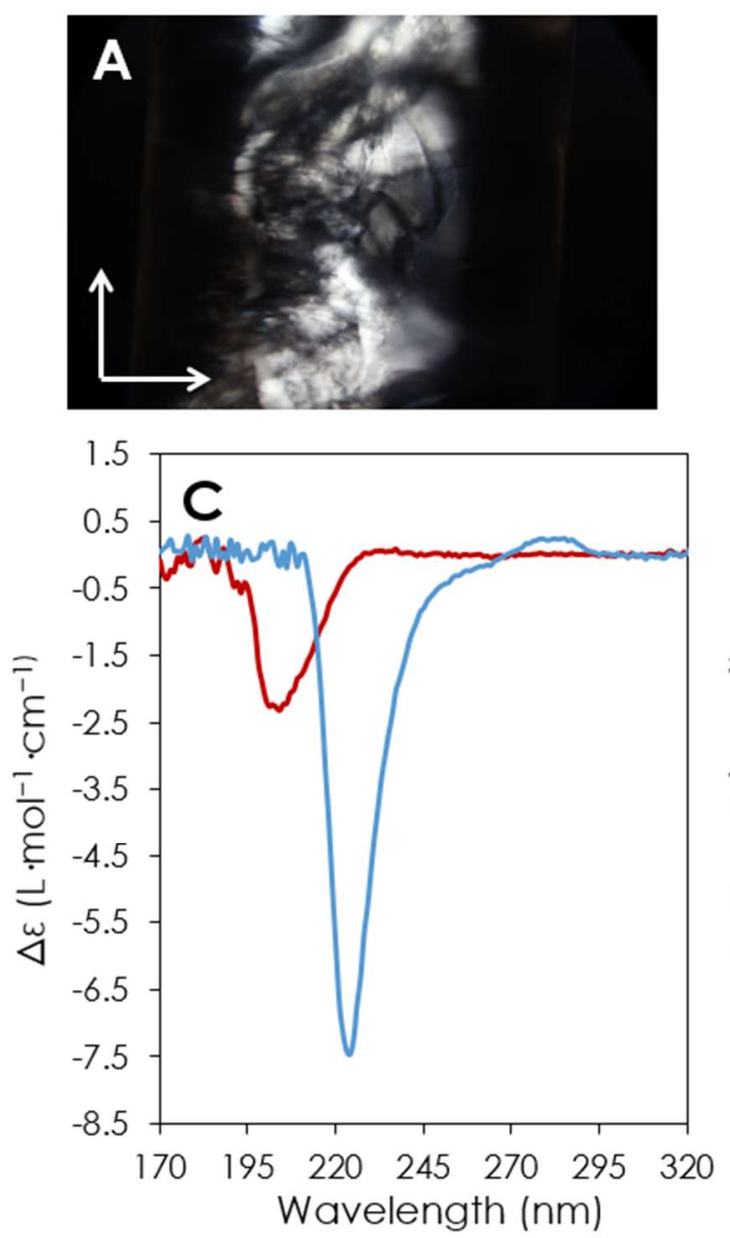
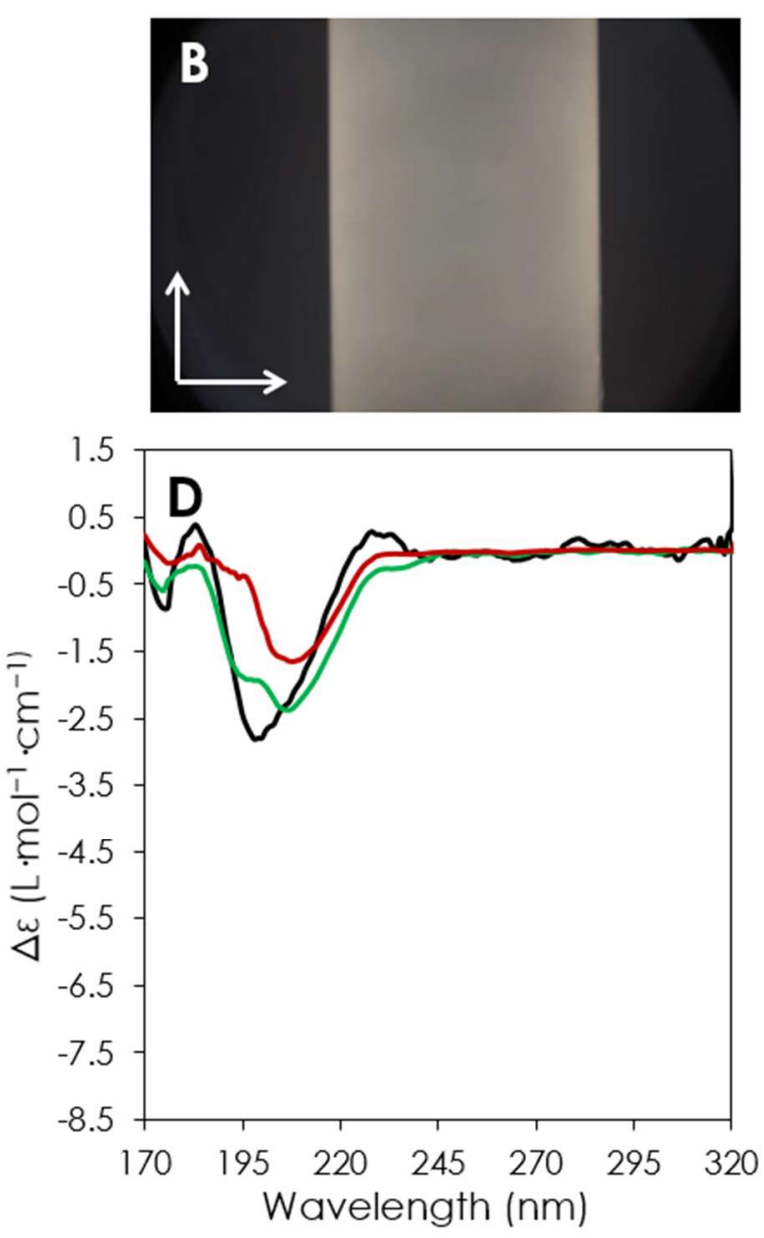

Figure 2 : A) Polarized light optical micrograph of $10 \%$ terlipressin solubilized in $0.15 \mathrm{M}$ sodium borate (pH 9.4) B) Polarized light optical micrograph of $10 \%$ terlipressin solubilized in $0.2 \mathrm{M} \mathrm{NaOH}$ (pH 13). C) SRCD spectra of $10 \%$ w/w terlipressin in 0.2 $\mathrm{M}$ acetic acid (red trace) and $0.2 \mathrm{M} \mathrm{NaOH}$ (blue line). D) SRCD spectra of terlipressin solubilized in $\mathrm{NH}_{4} \mathrm{Ac} \mathrm{pH} 9$ at $1 \% \mathrm{w} / \mathrm{w}$ (black line), 5\%w/w (green trace) and 10\%w/w (red trace).

An intermediate case between these two reference spectra is illustrated by Figure 2D exhibiting the spectra of three solutions solubilized in $0.2 \mathrm{M} \mathrm{NH}_{4} \mathrm{Ac}(\mathrm{pH}=9)$ at $1 \%, 5 \%$ and $10 \% \mathrm{w} / \mathrm{w}$. The $1 \% \mathrm{w} / \mathrm{w}$ liquid solution yields a spectrum with a negative band with a minimum at $200 \mathrm{~nm}$ (black trace) similar to that of the $10 \%$ solution in acetic acid, indicating that the peptide is under monomeric form. The $10 \% \mathrm{w} / \mathrm{w}$ gel solution yields a spectrum with a negative band whose minimum is shifted towards $209 \mathrm{~nm}$ (red trace) denoting the formation of $\beta$-sheet structures. At the intermediate $5 \% \mathrm{w} / \mathrm{w}$ concentration, the viscous solution yields a spectrum that looks like a composite of the two other spectra with a band with a double minimum at 197 and $208 \mathrm{~nm}$ (green trace). Overall, there is a correlation between the band position and the state of aggregation of the peptide. Peaks located around $200 \mathrm{~nm}$ correspond to liquid solutions where the peptide retains its monomeric form (for example $0.5 \% \mathrm{w} / \mathrm{w}$ in $0.2 \mathrm{M} \mathrm{NaOH}$ 
or $10 \% \mathrm{w} / \mathrm{w}$ in water) while peaks shifted to $210-230 \mathrm{~nm}$ correspond to gels where the peptide is in its assembled form (for example $10 \% \mathrm{w} / \mathrm{w}$ in $\mathrm{NaOH}$ ). All the situations in-between would indicate a coexistence between the monomers and the assembled form or the presence of intermediate structures in comparable proportions. Circular dichroism thus provides a rather sensitive qualitative assessment of the content of the solutions. Consequently, a slight shift in an apparently clear and liquid solution indicates a change of the peptide conformation and suggests the appearance of intermediate structures, possibly oligomers or short fibrils. More circular dichroism spectra are discussed in the supplementary information section.

Fourier-transform infrared spectroscopy (FTIR) also provides information on the peptide secondary structure. In particular, the $C=O$ stretching vibrations appearing in the amide I band region (1700-1600 $\mathrm{cm}^{-1}$ ) are modulated when the $\mathrm{H}$-bonds structuring the $\beta$ sheets are formed. ${ }^{46}$ The amide I band of $10 \%$ TLP solutions solubilized at different $\mathrm{pH}$ are presented in Figure 3A. Below pH 7.4, the spectra exhibit a broad peak centered at $1656 \mathrm{~cm}^{-1}$ in the amide I band region, indicating a mostly disordered organization of the peptide (black trace a). Indeed, a broad peak results from the combination of all the possible conformations accessible to the peptide in the solution. The peptide is most likely in its monomeric form or, at most, aggregated in poorly ordered structures. Above $\mathrm{pH} 8$, the spectra are clearly more structured (blue traces e and f). The deconvolution of the amide I band region by the second derivative method yields four Gaussian contributions (Figure 3C) that can be assigned through empirical correlation with the literature. ${ }^{47,47}$ The strongest peak at $1634 \mathrm{~cm}^{-1}$ suggests a parallel $\beta$-sheet arrangement. 48 The narrow bandwidths indicate a stable and/or long $\beta$-strands and strong hydrogen bonds as expected for repetitive structures such as amyloid fibers. The peak at $1656 \mathrm{~cm}^{-1}$ is ascribed to the random conformations of the free peptides remaining in the solution. The peak at $1674 \mathrm{~cm}^{-1}$ could be the signature from a $\beta$-turn originating from the cyclic structure of the peptide. ${ }^{49}$ Finally, the last peak at $1617 \mathrm{~cm}^{-1}$ has been assigned to aggregated $\beta$-sheet strands and/or side chains. ${ }^{50}$ It is interesting to note that at intermediary $\mathrm{pH}$ levels ( $\mathrm{pH}$ 7-7.4), an increase of the intensity is observed at $1630 \mathrm{~cm}^{-1}$, indicating a contribution of the parallel $\beta$-sheet structure in an overall disordered solution (green traces b and c). Likewise, the addition of PEG in the water solution yields an even more structured amide I band (purple trace d), suggesting depletion effects play a part in amyloid aggregation of TLP. 

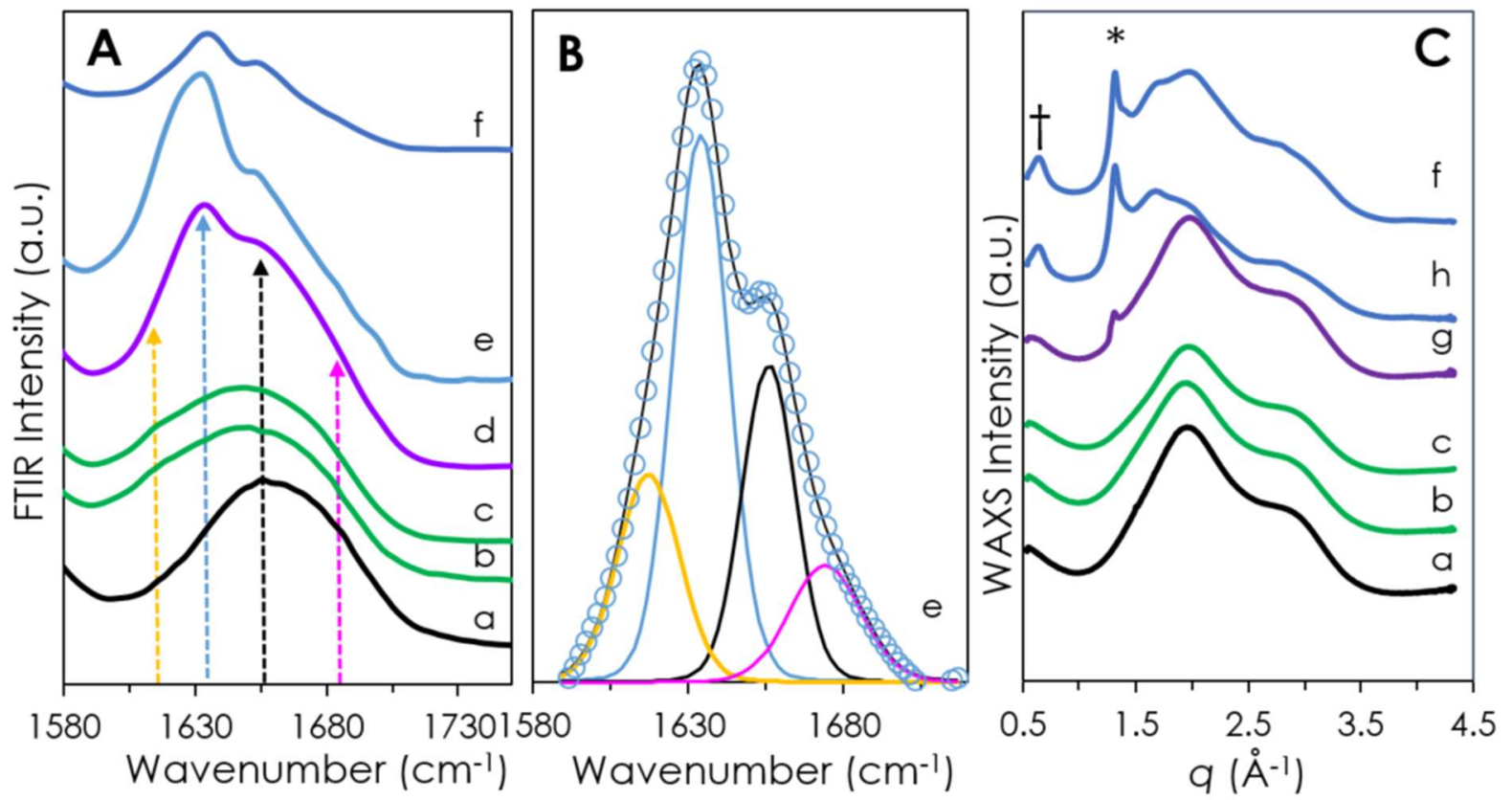

Figure 3 : ATR-FTIR and WAXS characterization of the concentrated TLP solutions. A) ATR-FTIR spectra as a function of the $\mathrm{pH}$ of the solution. a: water (pH 7.2), b: water+mannitol (pH 7.2), c: 100 mM PBS (pH 7.4), d: water + PEG (pH 7.2), e: 150 mM borate $(\mathrm{pH}$ 9), f: $200 \mathrm{mM} \mathrm{NaOH}(\mathrm{pH}$ 13). The dashed arrows indicate the positions of the main vibrations as determined by deconvolution. B) Amide I band deconvolution. The open circles represent the experimental data points (10\% TLP in $150 \mathrm{mM}$ borate) C) WAXS profiles of $10 \%$ TLP solution in different buffers (without water subtraction). a: water, b, water+mannitol, c: 100 mM PBS (pH 7.4), g: 100 mM PBS (pH 8), h: $\mathrm{NH}_{4} \mathrm{Ac}(\mathrm{pH} 11), \mathrm{f}: \mathrm{NaOH}(\mathrm{pH} 13)$. The star $\left(^{*}\right)$ and the dagger $(+)$ indicate the positions of respectively the meridional and the equatorial reflection of the $\beta$-sheet.

The organization of the TLP into $\beta$-sheets is confirmed by the wide angle $x$-ray scattering (WAXS) patterns displayed in Figure 3C where characteristic reflections at $1.31 \AA^{-1}$ and $0.63 \AA^{-1}$ are clearly visible at basic $\mathrm{pH}$ (blue traces $\mathrm{f} \& \mathrm{~h}$ ). These reflections correspond in the direct space to $4.8 \AA$ and $10 \AA$, which are respectively related to the hydrogen bonding distance between the $\beta$-strands and the repeat distance between the sheets. ${ }^{51}$ At intermediary $\mathrm{pH}$ levels ( $\mathrm{pH} 8$, violet trace $\mathrm{g}$ ), these two reflections are only feebly visible. At lower $\mathrm{pH}$ levels (black and clear green traces a, b \& c), only the broad diffusion peak of water is visible.

The distinct scattering intensities at small angles (Figure $4 \mathrm{~A}$ ) as a function of $\mathrm{pH}$ is also indicative of the variable proportion of amyloid structures forming in solutions. Mostly, the higher the $\mathrm{pH}$ level, the higher the scattering intensity at low scattering vector $q$. Below $\mathrm{pH}$ 7.4, a bump at $0.125 \AA^{-1}$ is visible, which we attribute to the correlation peak formed by the repulsive interaction between free monomers in solution. Such patterns can indeed be fitted by an assembly of $0.8 \mathrm{~nm}$ hard spheres in interaction (Figure 4B, black trace over red circles). Above $\mathrm{pH} 7.4$, the scattering curves tend towards a power law of $q^{-1}$, indicative of 1dimensional structures expected for amyloid fibrils. Indeed, these curves are convincingly 
fitted by a cylinder form factor of 1.8-2.5 nm radius (e.g. Figure $4 \mathrm{~B}$, black trace over blue circles). Interestingly, there is an isoscattering point at $0.125 \AA^{-1}$ that indicates the coexistence of two species whose concentrations are linked. These two species should be the TLP under a monomeric and an "aggregated" form. Indeed, as the solution is getting depleted in monomers (higher angles, on the right of the isoscattering point), it is proportionally enriched in aggregates (lower angles). Moreover, the increasing scattering intensity at small angles as the $\mathrm{pH}$ is increased indicates that the proportion of aggregates increases. The aggregation rate could thus be linked to the peptide state of charge that continuously decreases from +2 to -1 between $\mathrm{pH} 7$ and $\mathrm{pH} 12$.
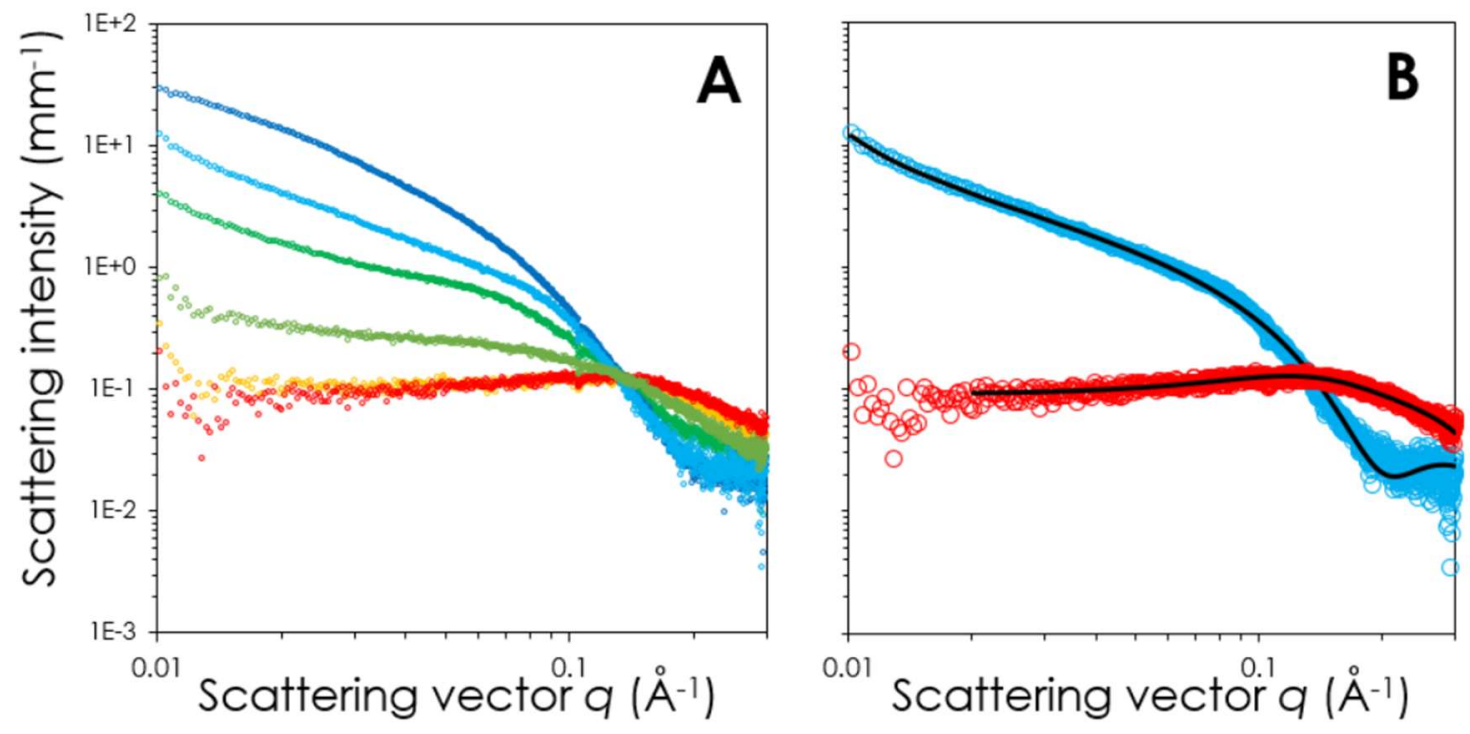

Figure 4: SAXS characterization of TLP samples as a function of $\mathrm{pH}$. A) SAXS profiles for $10 \%$ terlipressin solutions in different buffers. Red trace: acetic acid ( $\mathrm{pH} 2.5)$, orange trace: water $+5 \%$ mannitol ( $\mathrm{pH} 7.2)$, clear green trace: PBS (pH 7.4), dark green trace: PBS (pH 8), clear blue trace: $\mathrm{NaOH}(\mathrm{pH} 13)$, sodium borate $(\mathrm{pH}$ 9) B) Fits of the SAXS curve for the $10 \%$ terlipressin solution in acetic acid (open red circles) and and $\mathrm{NaOH}$ (open blue circles). The experimental curves can be modeled by respectively a sphere form factor with a repulsive structure factor and a cylindrical form factor.

These conclusions are upheld by cryoTEM observations that allowed a direct visualization of a thin film of basic TLP solutions free from drying artefacts (see SI for examples of dried TLP specimen). At a 10\%w/w concentration ( $\mathrm{pH} 9$ ), a very dense array of parallel thin fibrils is visible (Figure 5A-B). These fibrils are about 2-3 nm diameter. From the anisotropic Fourier-transform of the images, the spacing between them is estimated to 7-8 $\mathrm{nm}$. These dimensions are compatible with the cylinder diameter retrieved from the fit of the SAXS pattern $(3.8 \mathrm{~nm}$ )(Figure $5 \mathrm{C})$. Moreover, the WAXS part of the scattering curve exhibits the typical reflections of $\beta$-sheet structures, thus confirming the amyloid nature of these thin fibrils. 

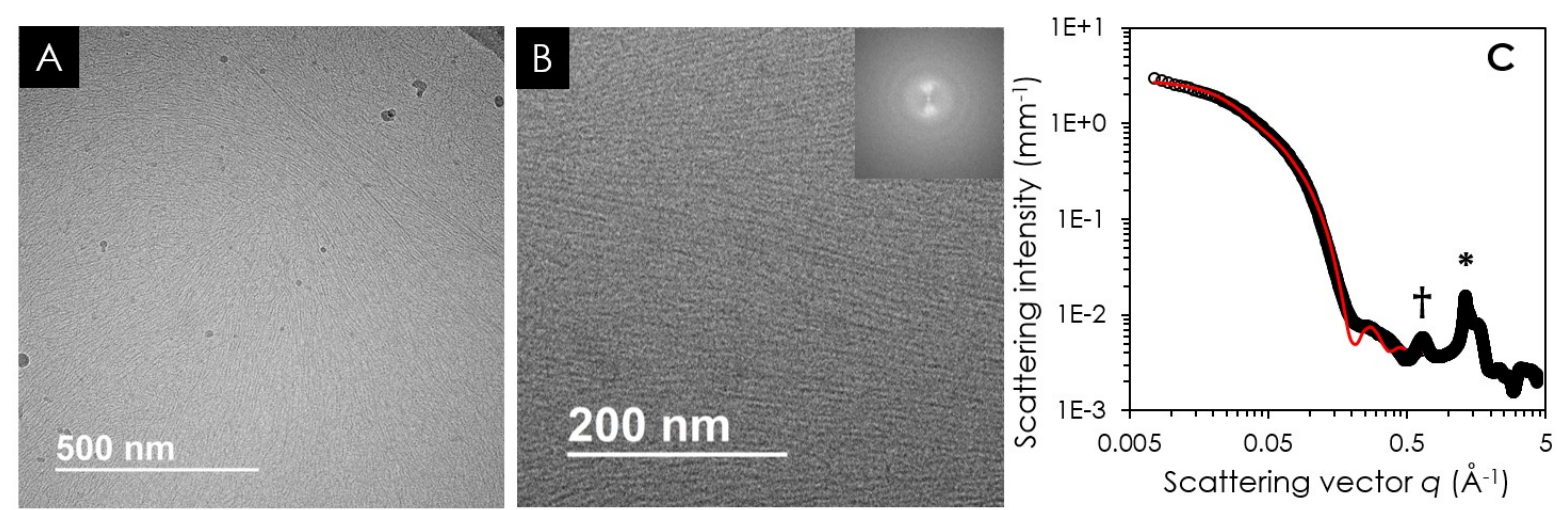

Figure 5 : CryoTEM observation A-B) Terlipressin 10\%w/w solubilized in $0.2 \mathrm{M} \mathrm{NH4Ac} \mathrm{(pH} \mathrm{9).} \mathrm{C)} \mathrm{Corresponding} \mathrm{SAXS-WAXS}$ pattern. Open black circles: experimental data, red trace: cylinder fit. The star $\left(^{*}\right)$ and the dagger $\left({ }^{\dagger}\right)$ indicate the positions of respectively the meridional and the equatorial reflection of the $\beta$-sheet.

\section{Monitoring the assembly kinetics}

Our preliminary visual observations have indicated that, at high enough concentrations, the aggregation process starts shortly after solubilization in the aqueous buffer. In order to gain insight on the mechanisms of peptide aggregation at basic $\mathrm{pH}$, we have followed the kinetics of assembly by ATR-FTIR spectroscopy and by combined SAXS-WAXS at the ESRF synchrotron source. Indeed, the clear solutions become viscous and gelify within a few minutes. For solutions at concentration above $10 \% \mathrm{w} / \mathrm{w}$ solubilized at $\mathrm{pH}$ higher than 12 , the whitening of the solution happens a few hours later. Overall, the samples seem to reach equilibrium within a day, which makes the use FTIR and SAXS appropriate.

\section{a) FTIR upon solubilization}

The solubilization process of $10 \% \mathrm{w} / \mathrm{w}$ TLP in $0.2 \mathrm{M} \mathrm{NaOH}$ was monitored by ATRFTIR. Quickly after solubilization of the lyophilized powder, a drop of the clear solution was deposited on the Zn-Se ATR crystal. To prevent evaporation, the drop was isolated from the atmosphere with a cell saturated with a solution of $0.2 \mathrm{M} \mathrm{NaOH}$ (Figure S4). Spectra were acquired every 10 minutes. A sampling of these spectra is displayed on Figure 6A. During the first couple of hours, the amide I band is not structured at all. From two hours and on, the peak at $1633 \mathrm{~cm}^{-1}$ is sharpening, indicating the increase of the $\beta$-sheet content in the sample. After 6 hours, the pattern does not change anymore. The intensity of this peak is plotted in Figure 6B. A typical sigmoid shape is observed, consistent with a nucleation-dependent polymerization mechanism. The plot could be reasonably fitted with a four-parameter logistic equation $I_{1633}=$ $A+\frac{B-A}{1+\left(\frac{C}{t}\right)^{D}}$, where $A$ and $B$ are the minimum and maximum values that can be obtained, $C$ indicates the $t$-value of the inflexion point, and $D$ is the slope of the curve at the point of 
inflexion. The induction period (or lag phase) of 30-40 minutes supposedly corresponds to the conformational conversion of the molecule and the amyloid nucleation. The steep increase corresponds to the rapid elongation phase during which the amyloid fibrils grow by addition of monomers.
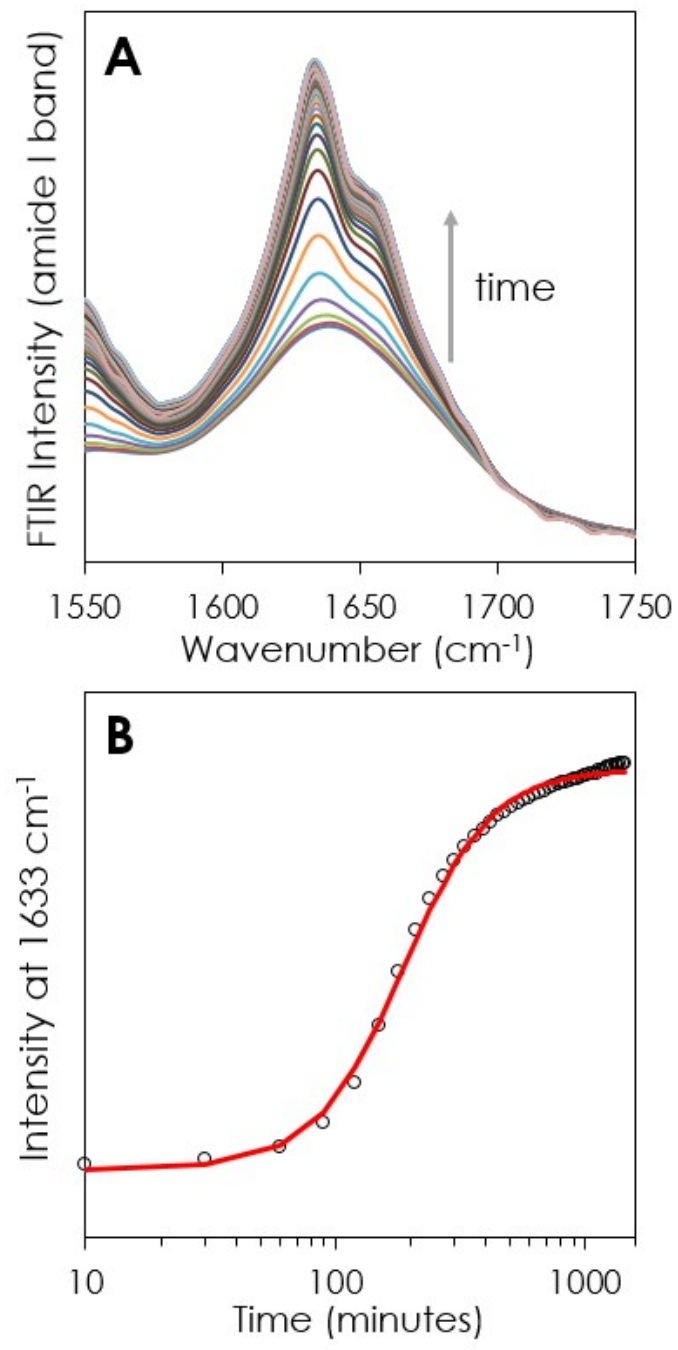

Figure 6: FTIR monitoring of $10 \% \mathrm{w} / \mathrm{w}$ TLP assembly upon solubilization in $0.2 \mathrm{M} \mathrm{NaOH}$. A) Evolution of the amide I band as a function of time. B) Plot of the intensity at $1633 \mathrm{~cm}^{-1}$ (open circles, every 30 minutes). The red line corresponds to the fit with a four parameter logistic equation.

b) SAXS-WAXS upon $\mathrm{pH}$ increase

Combined SAXS-WAXS was also used in order to characterize the different structures forming in the solution during the TLP aggregation process. Here, the aggregation was triggered by $\mathrm{pH}$ increase. The initial state is a $10 \%$ TLP solution solubilized in pure water ( $\mathrm{pH}$ 7) placed in a quartz capillary tube; a drop of ammonia solution is introduced in the same tube, keeping an air bubble between the two solutions as a separation (see Figure S5 in SI). The tube is then sealed with wax. As a consequence, the atmosphere inside the tube is saturated 
with ammonia vapours that will diffuse in the TLP solution and progressively increase its $\mathrm{pH}$. The TLP solution is then scanned with the x-ray beam along the gradient of diffusion several times over a course of 14 hours. The full series of SAXS and WAXS scans are shown in respectively Figure S6 and S7. The Figure 7, which exhibits the evolution in time of the SAXS pattern at a single position on the capillary, enables to identify different features apparent over time. The panel A exhibits the experimental SAXS patterns in absolute intensities. The different curve shapes observed during the assembly can be fitted using different models depending on the stage of the assembly process. These fits are plotted in the panel B in black traces over the merged experimental SAXS-WAXS patterns in open circles (this time the curves have been shifted for clarity). The models and main parameters used for the best fits are reported in Table 1.
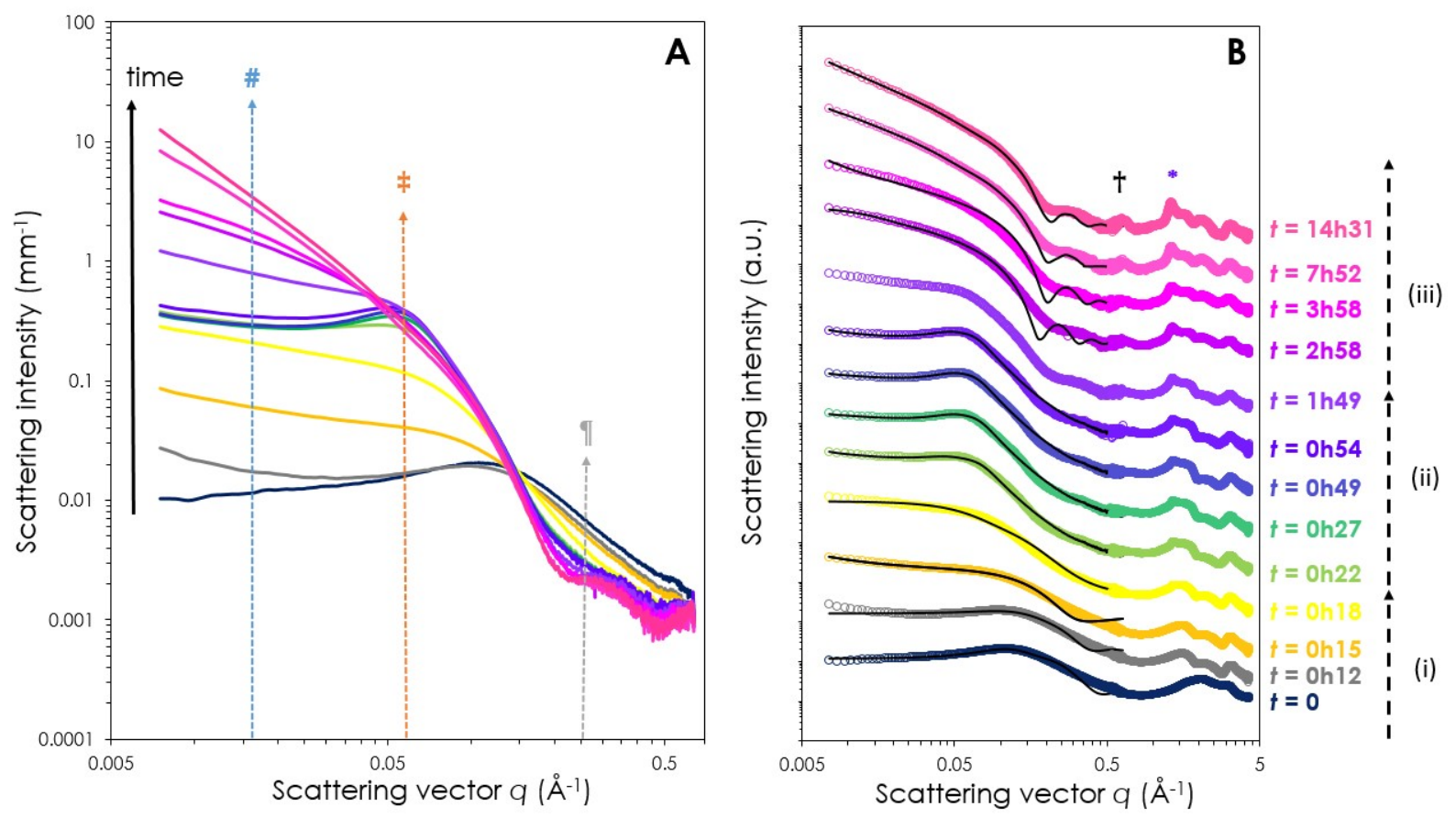

Figure 7: SAXS monitoring of the TLP assembly upon $\mathrm{pH}$ increase by ammonia vapours. A) SAXS profiles taken at the bottom of the capillary (far from the interface) as a function of time. The scattering pattern of water is the flat trace in clear blue. B) SAXS-WAXS profiles taken at the bottom of the capillary as a function of time (same as Figure 7A but with an offset for clarity). The open circles represent the experimental data, the linear traces the fits. See more details in the Table 1 . The positions of meridional and the equatorial reflections of the cross- $\beta$ sheets in the WAXS region are indicated with a star $\left({ }^{*}\right)$ and a dagger (†). The double dagger $(\ddagger)$ indicates a bump at $0.059 \AA^{-1}$ in intermediary SAXS profiles.

The scattering pattern of the initial $10 \% \mathrm{w} / \mathrm{w}$ TLP solution in water (" $t=0$ ", before the contact with ammonia vapour) exhibits a very broad peak centered at $0.12 \AA^{-1}$, which in direct space would correspond to a distance of $\sim 5 \mathrm{~nm}$ between two TLP monomers in the solution. This pattern can indeed be fitted by an assembly of repulsive spheres of radius $r=0.9 \mathrm{~nm}$, a value coherent with the peptide size. 
As soon as the TLP solution is in contact with ammonia vapours ( $t=0$ h12) the scattering intensity at low angles increases and the WAXS signal (Figure 7B) is modified, indicating respectively aggregation and changes in the monomer conformation. As the ammonia perfuses through the solution, the monomers aggregate into larger objects. These curves can no longer be fitted by simple spheres. We thus use a Beaucage ${ }^{52-54}$ fit showing that the hydrodynamic radius increases up to $2.5 \mathrm{~nm}$, denoting the aggregation of monomers into non-spherical structures. After 22 minutes, a correlation peak marked by double dagger ( $\ddagger)$ appears at $q=0.059 \AA^{-1}$ (i.e. $\sim 10.6 \mathrm{~nm}$ in direct space) denoting the interactions between the aforementioned aggregates. We then use a convolution of the experimental curve at $t=18$ minutes (considered as the form factor of the aggregates) and a lorentzian peak to fit the corresponding curves (see Figure 9$)$. At the same time $(t=0 \mathrm{~h} 22)$, in the WAXS region, the meridional reflection of the amyloid structures marked by a star $\left(^{*}\right)$ appears.

Finally, from $1 \mathrm{~h} 49$ and on, the scattering at small angles increases again while the amyloid reflection is now clearly marked, indicating the formation and growth of fibrils amidst the amorphous aggregates. The curve of this mixture at $t=1 \mathrm{~h} 49$ could not be simply fitted yet, but from 3 hours and on, the patterns can be fitted with a cylindrical form factor $(r$ $=1.9 \mathrm{~nm}$ ) indicating that the aggregates have disappeared, making way for the growth of amyloid fibrils. However, to obtain a better fit of the intermediate $q$-range, a broad peak accounting for the interaction between fibrils was introduced. Although at the end of the monitoring the sample was homogeneous all along the capillary as shown in the last panel of Figure S6, the sample had probably not reached its final state yet since the SAXS pattern is not yet the same as in Figure 5C. Indeed, the pattern in Figure 5C was obtained with a sample prepared a week before and can be fitted with only monodisperse cylinders.

One can also note that all the curves cross at the same scattering vector $q=0.14 \AA^{-1}$. Such an isosbestic points (here, isoscattering point) generally indicates the conversion of a species into another, e.g. the TLP monomers into larger assemblies (i.e. initially amorphous aggregates and afterwards amyloid fibrils). However, it is difficult to give a physical interpretation to the value of this isoscattering point. Several authors already discussed that point in the past. ${ }^{55-57}$

To better visualize the evolution of the different features discussed above, the absolute intensity at different scattering vectors is plotted as a function of time in Figure $8 \mathrm{~A} \& \mathrm{~B}$. In Figure 8A, the intensities of two specific features of the SAXS $q$-range are plotted as a function of time. First, a representative point in the power-law slopes $\left(q<0.04 \AA^{-1}\right.$; the specific scattering 
vector is indicated by sharp sign in Figure 7A). This plot highlights three steps: (i) a sharp increase in the first 25 minutes, (ii) a plateau lasting about an hour and (iii) a milder increase. The second plot monitors the intensity at $0.059 \AA^{-1}$ (indicated with a double dagger ( $\ddagger$ ) in Figure 7A) where a broad peak appears at intermediate times. Here too, three steps are visible. In the first two steps (i-ii), the plot superimposes with the previous one but the third one (iii) sees a decrease of intensity.
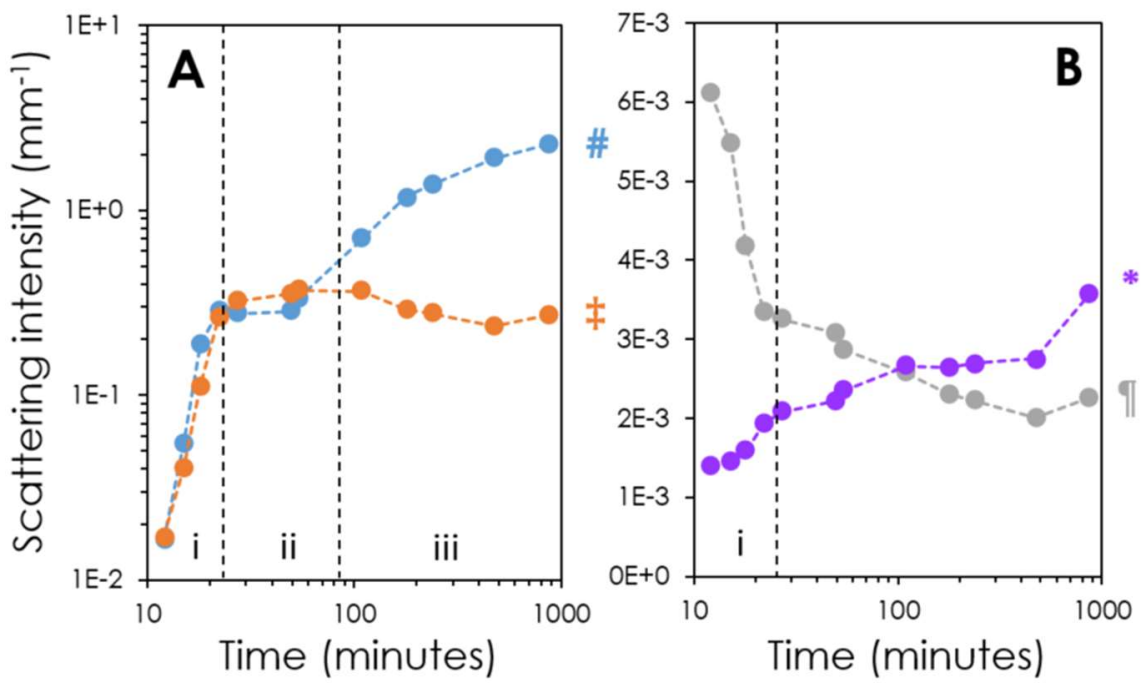

Figure 8: A) Plot of the absolute intensity at $0.021 \AA^{-1}$ (indicated by a sharp sign (\#) in Figure 7A) and at $0.06 \AA^{-1}$ (indicated by a double dagger ( $¥)$ in Figure $7 \mathrm{~A}$ ) as a function of time. B) Plot of the absolute intensity at $1.32 \AA^{-1}$ (indicated by a star $\left({ }^{*}\right)$ on the WAXS patterns and at $0.25 \AA^{-1}$ (indicated by a pilcrow sign (ף) in Figure 7A) as a function of time.

The Figure $8 \mathrm{~B}$ exhibits the decrease of the scattering intensity in the WAXS $q$-range after the isoscattering point (indicated by the pilcrow sign 9 in Figure 7A). Here, only two steps are visible: a strong decrease during the first 20 minutes followed by a milder decrease in the following hours. This suggest that a large fraction of monomers is rapidly consumed to form larger aggregates. The other fraction remains in equilibrium with the assembled species. By contrast, the intensity of the meridional reflection of the $\beta$-sheet in the WAXS region increases following a sigmoidal curve whose inflexion point corresponds to the end of the first step described in the other plots. This confirms that the amyloid structure is not readily present when the aggregates form but appears later. A sketch of these amorphous aggregates along with alleged cryo-TEM pictures are displayed in Figure 9. 


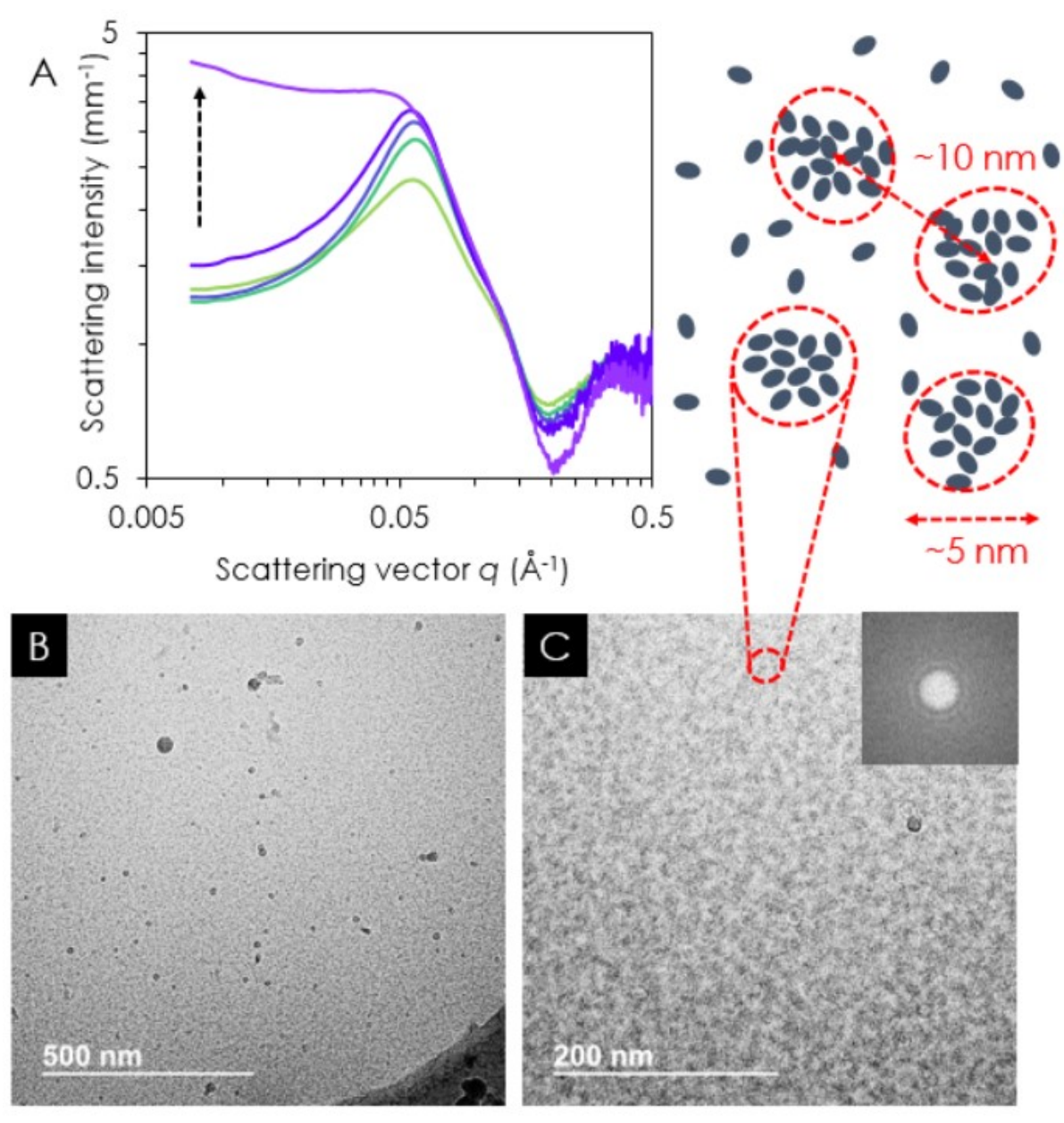

Figure 9 : Characterization of the intermediate amorphous phase. A) Structure factor of the SAXS patterns between 0 h22 and 1 h49 obtained by dividing the original SAXS patterns by the pattern at 0h18. The sketch represents the amorphous aggregates of TLP monomers in interaction in the solution. The strong increase of the scattering intensity at small angle in the pattern last pattern (1h49) indicated by a dashed arrow corresponds to the growth of the fibrils out of the amorphous aggregates. B-C) CryoTEM observations of an aged 7\% TLP sample solubilized in $0.2 \mathrm{M} \mathrm{NH}_{4} \mathrm{Ac} \mathrm{pH}$ 9. Inset: FFT of the panel D, indicating a characteristic distance of 5-10 nm. These amorphous structures might be equivalent to those observed with SAXS.

Table 1: Parameters used in Figure 7B to fit the SAXS patterns. During the course of the process, different models are used. Initially, only hard spheres in correlation represent the free monomers in the solution. The non-spherical amorphous aggregates are fiited using a BEaucage fit. When these aggregates enters in interaction, we used the experimental curve at 0 h18 as a form factor and only fit the structure factor. Finally, once the fibrils have appeared, a cylindrical form factor provide a good fit of the pattern. He fit is improve in the middle $q$-range by including a structure factor due to the interaction between the fibrils.

\begin{tabular}{|c|c|c|c|c|}
\hline Time & Fit Model & Radius (nm) & Cylinder radius (nm) & $X^{2}$ \\
\hline 0 & $\begin{array}{l}\text { Hard spheres + } \\
\text { correlation }\end{array}$ & $\begin{array}{c}r=0.9 \\
r_{\text {eff }}=2.4\end{array}$ & l & $4.85 \times 10^{-7}$ \\
\hline 0h12 & $\begin{array}{l}\text { Hard spheres + } \\
\text { correlation }\end{array}$ & $\begin{array}{c}r=1.1 \\
r_{\text {eff }}=2.1\end{array}$ & l & $9.01 \times 10^{-7}$ \\
\hline 0h15 & $\begin{array}{c}\text { Beaucage } \\
\text { (Unified Power } R_{\mathrm{g}} \text { ) }\end{array}$ & $r_{g}=1.6$ & l & $5.28 \times 10^{-6}$ \\
\hline 0h18 & $\begin{array}{c}\text { Beaucage } \\
\text { (Unified Power } R_{\mathrm{g}} \text { ) }\end{array}$ & $r_{g}=2.5$ & / & $3.59 \times 10^{-5}$ \\
\hline 0h22 & $\begin{array}{l}\text { Aggregate form factor* } \times \\
\text { structure factor }\end{array}$ & not fitted & / & $8.09 \times 10^{-5}$ \\
\hline 0h27 & $\begin{array}{l}\text { Aggregate form factor* } x \\
\text { structure factor }\end{array}$ & not fitted & / & $1.12 \times 10^{-4}$ \\
\hline
\end{tabular}




\begin{tabular}{ccccc}
\hline 0h49 & $\begin{array}{c}\text { Aggregate form factor } \\
\text { structure factor }\end{array}$ & not fitted & / & $1.24 \times 10^{-4}$ \\
\hline 0h54 & $\begin{array}{c}\text { Aggregate form factor } \\
\text { structure factor }\end{array}$ & not fitted & $/$ & $1.61 \times 10^{-4}$ \\
\hline 1h49 & Aggregates + cylinders & not fitted & not fitted & not fitted \\
\hline 2h58 & Cylinders & $/$ & 2.1 & $1.47 \times 10^{-4}$ \\
\hline 3h58 & Cylinders $\times$ broad peak & $/$ & 1.9 & $3.04 \times 10^{-3}$ \\
\hline 7h52 & Cylinders $\times$ broad peak & $/$ & 1.9 & $1.04 \times 10^{-6}$ \\
\hline 14h31 & Cylinders $\times$ broad peak & $/$ & 1.9 & $3.295 \times 10^{-5}$ \\
\hline A & Cylinders & $/$ & & 1.9
\end{tabular}

* the experimental SAXS pattern measured at $t=0 \mathrm{~h} 18$ was used as a form factor of the aggregates

** corresponds to the pattern shown in Figure 5C. The sample was prepared in $\mathrm{NaOH} \mathrm{0.2} \mathrm{M.}$

Also telling are the relative pair distance distribution functions $\mathrm{P}(r)$ plotted in Figure 10A (the full series is plotted in Figure S9). The $\mathrm{P}(r)$ functions give the probability of finding a point within the scattering particles at a distance $r$ from a given point. The blue trace corresponding to the liquid solution at $t=0$ has a rather narrow bell-shape centered at $\sim 1.5$ $\mathrm{nm}$, which would correspond to the TLP monomers. After 20 minutes (green trace), peptide aggregation has started, and the distribution function slightly widens - but remains symmetrical - and shifts towards larger sizes with a maximum distance $D_{\max }$ of $\sim 5.5 \mathrm{~nm}$. This distribution function could correspond to the size of amorphous aggregates similar to those shown in Figure 9. Finally, the pink trace shows a very wide distribution function with a $D_{\max }$ reaching $14 \mathrm{~nm}$ corresponds to the formation of the fibrils. One must note that the $D_{\max }$ is not representative of the full length of the fibrils, which is way beyond the range accessible by the experiment. The asymmetrical purple trace $(t=2 \mathrm{~h} 58)$, where the maximum population is located at $\sim 4 \mathrm{~nm}$ but whose $D_{\max }$ reaches $14 \mathrm{~nm}$, can be ascribed to an intermediate case in which the fibrils are coexisting with the amorphous aggregates. 

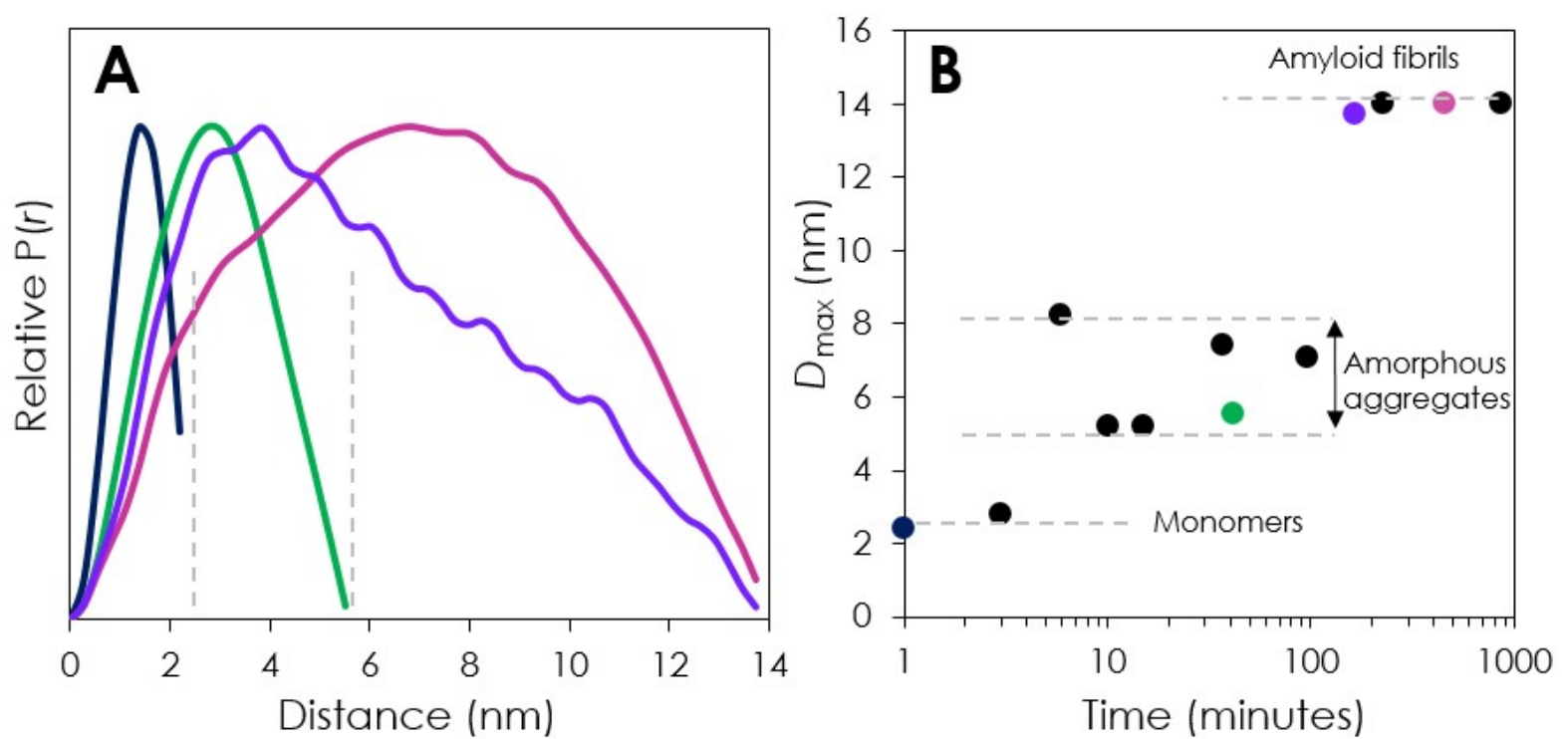

Figure 10 : A) Relative pair distribution functions calculated from some of the scattering curves presented in Figure 7A. For clarity, only the distribution functions at $t=0 \mathrm{~h} 00$ (blue trace), 0h54 (green trace), 2h44 (purple trace) and 7h40 (pink trace) are displayed. They are also scaled to a maximum value of 1 . The other curves are plotted in Figure S9. B) Plot of the maximum distance $\left(D_{\max }\right)$ in the pair distribution functions as a function of time. The coloured dots correspond the pair distribution function of panel $A$.

Similar conclusions were reached using a slightly different protocol: the TLP assembly was directly monitored by combined SAXS-WAXS over 12 hours right after solubilization of the peptide $(10 \% \mathrm{w} / \mathrm{w})$ in a $0.2 \mathrm{M} \mathrm{NH}_{4} \mathrm{Ac}$ at $\mathrm{pH}$ 9. These results and analyses are reported in the SI file, Figure S10 \& S11 and Table S1). Here again, the observed sequence of event consists of two steps : (i) a lag phase (<20 minutes) during which the monomers form amorphous aggregates, and (ii) a rapid growth step during which the fibrils of $1.9 \mathrm{~nm}$ radius form. After 30 minutes, the system has reached an equilibrium. In this case, however, the existence of the amorphous aggregates seems to be much more short-lived. Indeed, we did not catch the intermediate step where they enter into interaction.

Finally, taken altogether, all the SAXS patterns observed in this study suggest only a small variability in the TLP fibrils morphology. The standard fibril radius seems to be around $2 \mathrm{~nm}$. Additionally, the position of the WAXS reflections are stable all across the samples. At this stage, it is difficult to decipher between the role of the ions in the solution and the maturation effects, both parameters seeming to be involved.

Concerning the assembly mechanism, the results show that the fibrillation goes through a two-step aggregation. In a first step the monomers aggregate into disordered structures $(r \leq 5 \mathrm{~nm})$. From these amorphous aggregates, the amyloid $\beta$-sheet fibrils nucleate and grow. The first step lasts 20-30 minutes and corresponds to the duration of the lag phase observed by ATR-FTIR monitoring. 


\section{Reversibility assessment.}

Since the present investigation deals with a peptide whose activity is mediated by the interaction of their monomeric form with (GPCR) receptors and that our main assumption is that the amyloid aggregates are simply a storage means, their aggregation has to be reversible.

Placing the TLP basic gels in physical contact with a drop of glacial acetic acid results in the immediate clarification of the gel. To slow down this process, acidic vapour was used. Here, the vapour was produced by a solution of glacial acetic acid that saturates a closed chamber in which the open capillaries are placed. Because the disassembly process was supposedly slower than the aggregation process it was not monitored in situ. Instead, after 17 hours in contact with the acidic vapour in a closed chamber, the capillaries were scanned along the diffusion gradient with x-rays. The resulting SAXS-WAXS patterns for a 15\% TLP solution initially solubilized in $0.2 \mathrm{M} \mathrm{NaOH}$ are displayed on Figure 11. The patterns of the initial solution are traced in red. The SAXS part can be fitted by monodisperse cylinders of $2.1 \mathrm{~nm}$ radii and the WAXS part displays the typical amyloid reflections.
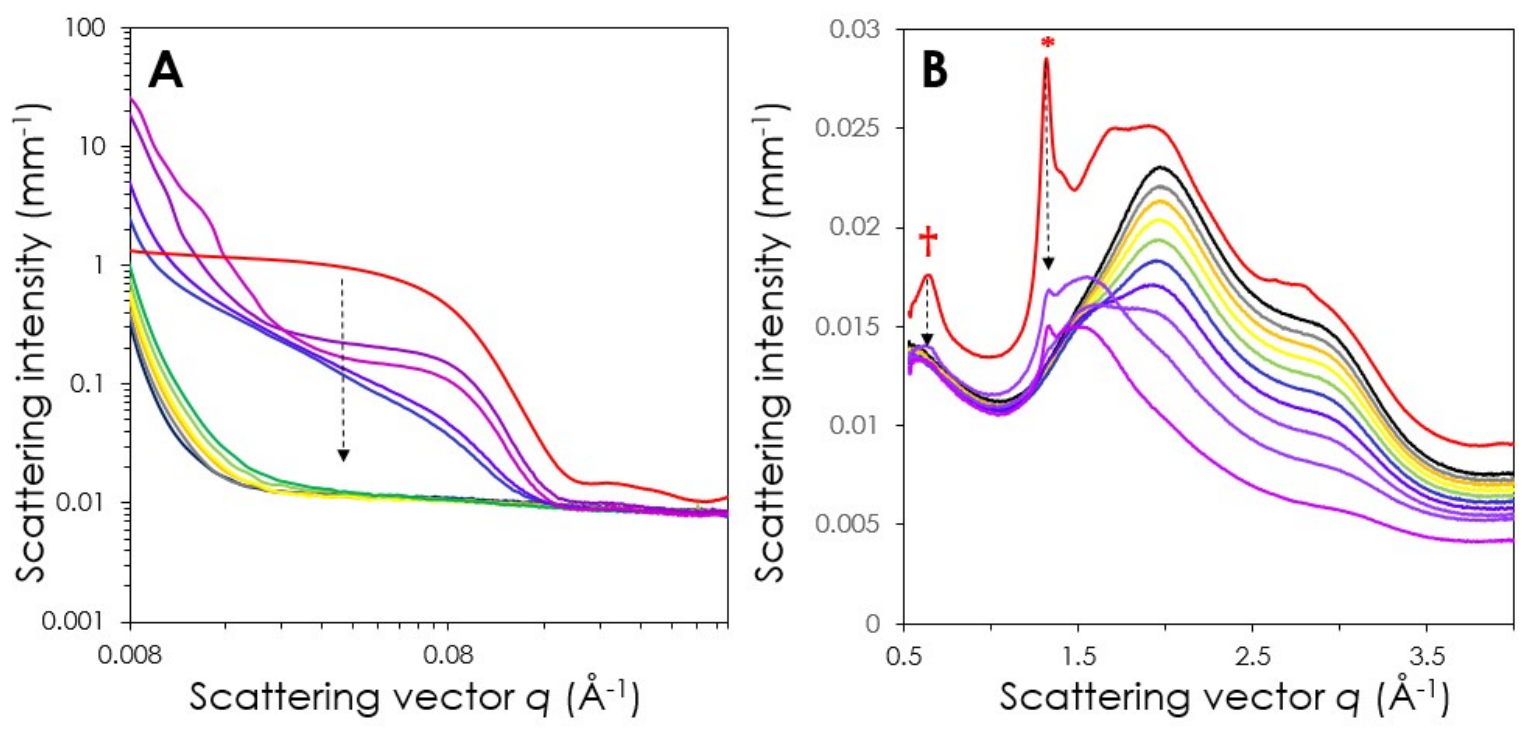

Figure 11 : Resolubilization of the fibrils with glacial acetic acid vapours. A) SAXS pattern. B) WAXS pattern. In this figure, the water profiles was not subtracted. The traces in red are the initial pattern of the $15 \% \mathrm{w} / \mathrm{w}$ TLP in NaOH, before the contact with acidic vapours. The traces in purple hues are the scattering patterns at the bottom of the capillary tube (far from the air/water interface), the other traces are the scattering pattern close to the interface. The star $\left({ }^{*}\right)$ and the dagger $\left({ }^{\dagger}\right)$ indicate the positions of respectively the meridional and the equatorial reflection of the $\beta$-sheet.

The patterns at the bottom of the figure (black-grey-yellow-green traces) correspond to the solution near the air-water interface and are completely superimposable to that of water scattering. The baseline in the $0.3-6 \mathrm{~nm}^{-1}$ region is flat indicating the disappearance of fibrils in 
the solution, as well as of TLP monomers (Figure 11A). Likewise, in the WAXS q-range (Figure 11B) the pattern is that of water. We can thus conclude that acidic vapour has completely dissolved the gel and that the peptide material has sedimented to the bottom of the capillary.

The patterns on the top of the figure (purple hues traces) correspond to the region of the capillary the farthest from the interface. The amyloid reflections at 4.65 and $10 \AA$ are still detectable in the WAXS q-range, albeit strongly attenuated (Figure 11B). Indeed, when the SAXS patterns (Figure 11A) are compared with the initial conditions (red traces), it appears clearly that the amyloid fibrils have already been partially dissolved. On the other hand, the increase of the scattering at very small angles witnesses the formation of large aggregates. Patterns in-between (blue traces) show the presence of aggregates whose amyloid features are no longer visible.

As a conclusion, if the amyloid fibrils are clearly dissolved by acidic vapours, it is not clear that the TLP monomers are recovered when using this method. Rather, we observed the sedimentation of larger disordered aggregates. This solubilization-reprecipitation process might simply be attributable to the high ionic strength caused by the accumulation of ions in the samples. The disassembly of the gels by dissolution in water is also possible but was not quantitatively assessed yet. As it was demonstrated with atosiban gels, we can expect that it is highly dependent on the concentration of the gels. ${ }^{28}$ Stirring of the dissolution bath is another important parameter. Given the density of the TLP gels at 15\% it should take several days to dissolve them completely.

\section{Discussion}

\section{Kinetics and mechanism of assembly}

We have performed structural investigations to delve into the assembly process of TLP into amyloid fibrils. If the nucleation and growth of amyloid $\beta$-sheets follow the typical sigmoidal pattern, concomitant observations with SAXS-WAXS suggest a specific two-step assembly mechanism. Indeed, instead of conformational changes (the TLP sequence being short and cyclic, there is little conformational space for unfolding/reorganization) and oligomeric associations occurring stochastically during the lag phase, we observe a rapid (within minutes) aggregation of the monomers into amorphous aggregates upon $\mathrm{pH}$ increase. Given that the radius of these amorphous aggregates is larger than that of the amyloid fibrils, they cannot be considered as nuclei nor prefibrillar oligomers as in the nucleated conformational conversion mechanism. We rather view this phenomenon as a liquid-liquid 
phase separation, which is reminiscent of the formation of amorphous precursor phases that has been described in non-classical nucleation of mineral crystals. ${ }^{58,59}$ The typical features of amyloid $\beta$-sheets (formation of a peak at $1633 \mathrm{~cm}^{-1}$ in FTIR and growth of reflections at 4.5 and $10 \AA^{-1}$ in WAXS) rise secondly from this amorphous network, the proximity of the molecules in the dense phase probably facilitating the nucleation of $\beta$-sheet rich amyloid structures. Only slightly later the cylindrical form factor of the fibrils emerges from the SAXS patterns as the scattering from the amorphous aggregates recedes.

These mature fibrils have a distinctive radius of $\sim 2 \mathrm{~nm}$. When the assembly is triggered by ammonia vapours, the duration of the induction time is both dictated by the diffusion of the ammonia in the sample (and thus the decrease of the peptide-peptide repulsion) and the nuclei of amyloid fibrils in the amorphous aggregates. Here, both the size and the lifetime of the intermediate species are clearly defined, leading to fibrils population with little to no polymorphism as shown in cryoTEM pictures (Figure 5). The TLP assembly mechanism thus follows a rather straightforward route when compared to other amyloid mechanisms reported in the literature that imply dramatic intramolecular conformational conversions, structural heterogeneities, and multiple steps. ${ }^{13}$

\section{Biological and biomedical implications}

Despite the presence of a proline and three glycines that are known to disrupt secondary structures (and particularly $\beta$-sheets) ${ }^{11}$ in the TLP sequence, TLP proved to be able to assemble spontaneously into amyloid fibrils in appropriate (mostly basic) buffers. It thus adopts a very similar behavior as its parent hormone vasopressin. ${ }^{11}$ TLP remains a very soluble peptide and the critical aggregation concentration is about a few percent $(w / w)$ depending on the $\mathrm{pH}$ level and the nature of the buffer. Surprisingly, whereas the $\mathrm{pH}$ levels in secretory granules are rather $\operatorname{acidic}^{9}$ (e. g. in the case of insulin ${ }^{60}$ ), in our study the amyloid formation of TLP is triggered by an increase of $\mathrm{pH}$. Nevertheless, in vivo, the hormone aggregation may also involve helper molecules and specific ionic interactions that modify the phase diagram.

On another level, TLP amyloid aggregation could be used as drug formulation. Indeed, although peptides have played a notable role in medicine (in the endocrinology field, but not only) since the introduction of insulin therapies in the 1920s and that their delivery relies on self-assembly ${ }^{41,61}$ or hydrogel loading62, very few applications have directly taken advantage of the self-assembling properties of peptide hormones, leading to a "self-formulation" of the 
peptide hormone. ${ }^{20,22-24}$ Yet, more and more physico-chemical studies have demonstrated that hormones or hormone-like peptide self-assemble into reversible amyloid hydrogels or microcrystals: the cases of lanreotide 33,37 , somatostatine ${ }^{38,63} \mathrm{GnRH}^{64}$ and $\mathrm{GnRH}$ analogues ${ }^{21}$, insulin 65,66 , cholecystokinin- $4{ }^{67}$ or atosiban ${ }^{28}$ can be mentioned. Since the TLP assembly could be used as a controlled release delivery system, it could be noteworthy to mention that several studies suggest that the activation of central vasopressinergic system may play a beneficial role for the prevention and treatment of cognitive impairments in rats. ${ }^{68-70}$

Finally, the absence of off-pathway polymorphic oligomeric species, which are commonly held responsible for the amyloid toxicity ${ }^{71}$, is congruent with a beneficial use of TLP fibrils.

\section{Conclusion}

In the present study, we have investigated the $\mathrm{pH}$-triggered amyloid formation of a 12 amino acid cyclic peptide. By combining circular dichroism, ATR-FTIR, SAXS-WAXS and cryo-TEM analyses, a rather simple mechanism emerges. While circular dichroism, ATR-FTIR and WAXS suggest a classical monomer-to-fibrils conversion after a lag phase, SAXS and cryoTEM characterizations evidence the formation of amorphous aggregates during the lag phase, in which the amyloid $\beta$-sheet structures will nucleate and grow. Both amorphous aggregates and mature fibrils seem to have rather well-defined size of respectively $2.5 \mathrm{~nm}$ and $1.9 \mathrm{~nm}$ in radius. As expected for a hormone-like peptide, these amyloid structures can be dissolved by reversing the $\mathrm{pH}$.

\section{Materials and methods}

Peptides. Terlipressin-actetate (triglycine-lysine vasopressin, TLP) was purchased from Bachem as a lyophilized power. Its amino sequence is H-Gly-Gly-Gly-Cys-Tyr-Phe-Gln-AsnCys-Pro-Lys-Gly- $\mathrm{NH}_{2}$ acetate salt. The TLP solutions were prepared by weighing the lyophilized powder and dissolving it in the appropriate aqueous buffer at room temperature. Fluorescence measurements. Solutions were filled in Hellma quartz Ultra-Micro cells and inserted in Cary Eclipse fluorimeter (Varian, Oxford, UK) for measurements. The samples were excited at $289 \mathrm{~nm}$ and emission scans were collected between 300 and $550 \mathrm{~nm}$ range. Excitation and emission slits were both set to $5 \mathrm{~nm}$. The scan rates were set to $120 \mathrm{~nm} \mathrm{~min}{ }^{-1}$ with $1 \mathrm{~nm}$ data interval and an averaging time of $0.5 \mathrm{~s}$. 
Attenuated Total Reflection Fourier Transform Infrared Spectroscopy (ATR-FTIR). ATRFTIR spectra were recorded at a $2-\mathrm{cm}^{-1}$ resolution with a Bruker IFS 66 spectrophotometer equipped with a $45^{\circ} \mathrm{N}$ ZnSe ATR attachment. The spectra obtained resulted from the average of 30 scans and were corrected for the linear dependence on the wavelength of the absorption measured by ATR. The water signal was removed by subtraction of pure water spectrum. Analysis of the conformations of the peptides was performed by deconvolution of the absorption spectra as a sum of Gaussian components with PeakFit 4.12 (Seasolve Software Inc.).

Synchrotron Radiation Circular Dichroism (SRCD). $4 \mu \mathrm{L}$ droplets or gel with spatula in CaF2 cells (Hellma). The path length used was $3.7 \mu \mathrm{m}$. The measurements were performed on the DISCO Beamline at the SOLEIL synchrotron (Saint Aubin, France). ${ }^{72,73}$ The raw spectra were acquired with a $1 \mathrm{~nm}$ spectral resolution and were analyzed with CDTool. ${ }^{74}$. The spectra presented in this study are the average of three spectra. A background (water or corresponding buffer spectrum acquired in the same conditions) was subtracted from them. The calibration was obtained with a CSA sample. Intensities were converting from millidegrees ( $\theta$ machine units) into $\Delta \varepsilon$ using the formula $\Delta \varepsilon=\theta * \frac{0.1 * \mathrm{MRW}}{3298 * 1 * \mathrm{C}^{\prime}}$, where MRW is the mean residue weight of the peptide (protein weight/number of residues $=102.3 \mathrm{Da}$ in the case of terlipressin), $l$ is the path length of the $\mathrm{CaF}_{2}$ cell in $\mathrm{cm}$ and $C$ is the peptide concentration in $\mathrm{mg} / \mathrm{ml}$.

Cryogenic transmission electron microscopy (cryo-TEM). The aggregated peptide solutions were observed by cryogenic transmission electron microscopy. Drops of the solutions were deposited on EM grids covered with a holey carbon film (Quantifoil R2/2) previously treated with a plasma glow discharge. The excess liquid on the grids was blotted out with filter paper, and the grids were quickly immersed in liquid ethane to form a thin vitreous ice film. The whole process was performed using a Vitrobot apparatus (FEI Company). Observations were conducted at low temperature $\left(-180{ }^{\circ} \mathrm{C}\right)$ on a JEOL $2010 \mathrm{FEG}$ microscope operated at $200 \mathrm{kV}$. Images were recorded with a Gatan camera.

Small and Wide Angle X-ray Scattering (SAXS/WAXS). Peptide solutions were inserted in $1.5 \mathrm{~mm}$-diameter quartz capillary tubes just after peptide solubilization and much as possible before gelification. The capillary tubed were sealed with wax to avoid evaporation. SAXS experiments exhibited in Figure 4 were collected with an in-house set-up equipped with a 
copper anode. The wavelength of the incident beam was $1.5418 \AA$. The scattered patterns were collected on a Pilatus detector. The sample-to-detector distance was $112 \mathrm{~cm}$. The absolute scattered intensities were scaled using Lupolen as a reference and following the method fully described in Zemb et al. ${ }^{75}$

Other SAXS-WAXS experiments (Figure 3C, Figure 5C and Figure 7-Figure 11) were performed at the European Synchrotron Facility (ESRF) in Grenoble on the ID02 beamline. The wavelength of the incident beam was $0.0995 \mathrm{~nm}$ with exposure times of the order of 0.1-0.5 s. The scattered x-ray were collected on two Rayonix 2D-detectors, covering respectively the $\left[0,075-6,408 \mathrm{~nm}^{-1}\right]$ and $\left[5,307-43,323 \mathrm{~nm}^{-1}\right] q$-ranges. No radiation damage was observed after repeated irradiations.

The SAXS 2D profiles were fitted with the software SASView 5.0 (http://sasview.org/) using the model functions for spheres, cylinders and hard sphere structure factor.

Electronic Supplementary Information available: additional CD characterizations in water and $\mathrm{NH}_{4} \mathrm{Ac}$ buffer ( $\mathrm{pH} 8$ ), conventional transmission electron microscopy images, ATR-FTIR set-up, Kratky plots and SAXS-WAXS monitoring of the TLP assembly upon solubilization in $0.2 \mathrm{M} \mathrm{NH}_{4} \mathrm{Ac}(\mathrm{pH} 9)$.

\section{Acknowledgments}

SAXS-WAXS experiments were performed on beamline ID02 at the European Synchrotron Radiation Facility (ESRF), Grenoble, France (proposal SC-4163). We are also grateful to Sylvain Prevost for his assistance during the session. SRCD experiments were performed on the DISCO Beamline at the SOLEIL synchrotron (Saint Aubin, France) (proposal 20150680). CryoTEM observations were made thanks to "Investissements d'Avenir" LabEx PALM (ANR-10LABX-0039-PALM). Maïté Paternostre is acknowledged for the access to the "TEM-team" platform (iBiTec-S/SB2SM). This work benefited from the use of the SasView application (http://www.sasview.org), originally developed under NSF award DMR-0520547. SasView contains code developed with funding from the European Union's Horizon 2020 research and innovation programme under the SINE2020 project, grant agreement no. 654000. 


\section{REFERENCES}

(1) Chiti, F.; Dobson, C. M. Protein Misfolding, Functional Amyloid, and Human Disease. Annu. Rev. Biochem. 2006, 75, 333-366.

(2) Chiti, F.; Dobson, C. M. Protein Misfolding, Amyloid Formation, and Human Disease: A Summary of Progress Over the Last Decade. Annu. Rev. Biochem. 2017, 86, 27-68. https://doi.org/10.1146/annurev-biochem-061516-045115.

(3) Fowler, D. M.; Koulov, A. V.; Balch, W. E.; Kelly, J. W. Functional Amyloid - from Bacteria to Humans. Trends in Biochemical Sciences 2007, 32 (5), 217-224. https://doi.org/10.1016/j.tibs.2007.03.003.

(4) Greenwald, J.; Riek, R. Biology of Amyloid: Structure, Function, and Regulation. Structure 2010, 18 (10), 1244-1260. https://doi.org/10.1016/j.str.2010.08.009.

(5) Maji, S. K.; Perrin, M. H.; Sawaya, M. R.; Jessberger, S.; Vadodaria, K.; Rissman, R. A.; Singru, P. S.; Nilsson, K. P. R.; Simon, R.; Schubert, D.; Eisenberg, D.; Rivier, J.; Sawchenko, P.; Vale, W.; Riek, R. Functional Amyloids As Natural Storage of Peptide Hormones in Pituitary Secretory Granules. Science 2009, 325 (5938), 328-332. https://doi.org/10.1126/science.1173155.

(6) Dannies, P. S. Prolactin and Growth Hormone Aggregates in Secretory Granules: The Need to Understand the Structure of the Aggregate. Endocrine Reviews 2012, 33 (2), 254 270. https://doi.org/10.1210/er.2011-1002.

(7) Malandrino, N.; Smith, R. J. Synthesis, Secretion, and Transport of Peptide Hormones. In Principles of Endocrinology and Hormone Action; Belfiore, A., LeRoith, D., Eds.; Springer International Publishing: Cham, 2018; pp 29-42. https://doi.org/10.1007/978-3-31944675-2_3.

(8) Lodish, H.; Berk, A.; Zipursky, S. L.; Matsudaira, P.; Baltimore, D.; Darnell, J. Overview of the Secretory Pathway. Molecular Cell Biology. 4th edition 2000.

(9) Seuring, C.; Nespovitaya, N.; Rutishauser, J.; Spiess, M.; Riek, R. Hormone Amyloids in Sickness and in Health. In Amyloid Fibrils and Prefibrillar Aggregates; Otzen, D. E., Ed.; Wiley-VCH Verlag GmbH \& Co. KGaA: Weinheim, Germany, 2013; pp 395-410. https://doi.org/10.1002/9783527654185.ch18.

(10) Birk, J.; Friberg, M. A.; Prescianotto-Baschong, C.; Spiess, M.; Rutishauser, J. Dominant Pro-Vasopressin Mutants That Cause Diabetes Insipidus Form Disulfide-Linked Fibrillar Aggregates in the Endoplasmic Reticulum. J Cell Sci 2009, 122 (21), 3994-4002. https://doi.org/10.1242/jcs.051136.

(11) Beuret, N.; Hasler, F.; Prescianotto-Baschong, C.; Birk, J.; Rutishauser, J.; Spiess, M. Amyloid-like Aggregation of Provasopressin in Diabetes Insipidus and Secretory Granule Sorting. BMC Biology 2017, 15 (1), 5. https://doi.org/10.1186/s12915-017-0347-9.

(12) Wetzel, R. Kinetics and Thermodynamics of Amyloid Fibril Assembly. Acc. Chem. Res. 2006, 39 (9), 671-679. https://doi.org/10.1021/ar050069h.

(13) Chatani, E.; Yamamoto, N. Recent Progress on Understanding the Mechanisms of Amyloid Nucleation. Biophys Rev 2018, 10 (2), 527-534. https://doi.org/10.1007/s12551017-0353-8.

(14) Serio, T. R.; Cashikar, A. G.; Kowal, A. S.; Sawicki, G. J.; Moslehi, J. J.; Serpell, L.; Arnsdorf, M. F.; Lindquist, S. L. Nucleated Conformational Conversion and the Replication of Conformational Information by a Prion Determinant. Science 2000, 289 (5483), 1317-1321. https://doi.org/10.1126/science.289.5483.1317. 
(15) Vestergaard, B.; Groenning, M.; Roessle, M.; Kastrup, J. S.; de Weert, M. van; Flink, J. M.; Frokjaer, S.; Gajhede, M.; Svergun, D. I. A Helical Structural Nucleus Is the Primary Elongating Unit of Insulin Amyloid Fibrils. PLoS Biology 2007, 5 (5), e134. https://doi.org/10.1371/journal.pbio.0050134.

(16) Oliveira, C. L. P.; Behrens, M. A.; Pedersen, J. S.; Erlacher, K.; Otzen, D.; Pedersen, J. S. A SAXS Study of Glucagon Fibrillation. Journal of Molecular Biology 2009, 387 (1), 147161. https://doi.org/10.1016/j.jmb.2009.01.020.

(17) Ortore, M. G.; Spinozzi, F.; Vilasi, S.; Sirangelo, I.; Irace, G.; Shukla, A.; Narayanan, T.; Sinibaldi, R.; Mariani, P. Time-Resolved Small-Angle x-Ray Scattering Study of the Early Stage of Amyloid Formation of an Apomyoglobin Mutant. Phys. Rev. E 2011, 84 (6), 061904. https://doi.org/10.1103/PhysRevE.84.061904.

(18) Groenning, M.; Campos, R. I.; Hirschberg, D.; Hammarström, P.; Vestergaard, B. Considerably Unfolded Transthyretin Monomers Preceed and Exchange with Dynamically Structured Amyloid Protofibrils. Scientific Reports 2015, 5, 11443. https://doi.org/10.1038/srep11443.

(19) Chatani, E.; Inoue, R.; Imamura, H.; Sugiyama, M.; Kato, M.; Yamamoto, M.; Nishida, K.; Kanaya, T. Early Aggregation Preceding the Nucleation of Insulin Amyloid Fibrils as Monitored by Small Angle X-Ray Scattering. Scientific Reports 2015, 5 (1), 1-14. https://doi.org/10.1038/srep15485.

(20) Cherif-Cheikh, R.; Bismuth, F.; Torres, M.-L.; Alloza, R.; Bosch, M. T.; Montes, M.; Fuster, E.; Valles, J.; Cordero, J. A.; Peraire, C.; Obach, R.; Antonijoan, R. Autogel: A New Lanreotide Prolonged Release Formulation. Proc. Int. Symp. Control. Rel. Bio. Mat. 1998, 25, 798-799.

(21) Maji, S. K.; Schubert, D.; Rivier, C.; Lee, S.; Rivier, J. E.; Riek, R. Amyloid as a Depot for the Formulation of Long-Acting Drugs. PLOS Biology 2008, 6 (2), e17. https://doi.org/10.1371/journal.pbio.0060017.

(22) Pertinhez, T. A.; Conti, S.; Ferrari, E.; Magliani, W.; Spisni, A.; Polonelli, L. Reversible Self-Assembly: A Key Feature for a New Class of Autodelivering Therapeutic Peptides. Mol. Pharmaceutics 2009, 6 (3), 1036-1039. https://doi.org/10.1021/mp900024z.

(23) Gupta, S.; Chattopadhyay, T.; Pal Singh, M.; Surolia, A. Supramolecular Insulin Assembly II for a Sustained Treatment of Type 1 Diabetes Mellitus. Proceedings of the National Academy of Sciences 2010, 107 (30), 13246-13251. https://doi.org/10.1073/pnas.1005704107.

(24) Ouberai, M. M.; Dos Santos, A. L. G.; Kinna, S.; Madalli, S.; Hornigold, D. C.; Baker, D.; Naylor, J.; Sheldrake, L.; Corkill, D. J.; Hood, J.; Vicini, P.; Uddin, S.; Bishop, S.; Varley, P. G.; Welland, M. E. Controlling the Bioactivity of a Peptide Hormone in Vivo by Reversible Self-Assembly. Nature Communications 2017, 8 (1). https://doi.org/10.1038/s41467-017-01114-1.

(25) Keeler, C.; Hodsdon, M. E.; Dannies, P. S. Is There Structural Specificity in the Reversible Protein Aggregates That Are Stored in Secretory Granules? Journal of Molecular Neuroscience 2004, 22 (1), 43-49.

(26) Pouget, E.; Fay, N.; Dujardin, E.; Jamin, N.; Berthault, P.; Perrin, L.; Pandit, A.; Rose, T.; Valéry, C.; Thomas, D.; Paternostre, M.; Artzner, F. Elucidation of the Self-Assembly Pathway of Lanreotide Octapeptide into $\beta$-Sheet Nanotubes: Role of Two Stable Intermediates. Journal of the American Chemical Society 2010, 132 (12), 4230-4241. https://doi.org/10.1021/ja9088023. 
(27) Gobeaux, F.; Fay, N.; Tarabout, C.; Mériadec, C.; Meneau, F.; Ligeti, M.; Buisson, D.-A.; Cintrat, J.-C.; Nguyen, K. M. H.; Perrin, L.; Valéry, C.; Artzner, F.; Paternostre, M.

Structural Role of Counterions Adsorbed on Self-Assembled Peptide Nanotubes. Journal of the American Chemical Society 2012, 134 (1), 723-733. https://doi.org/10.1021/ja210299g.

(28) Gobeaux, F.; Wien, F. Reversible Assembly of a Drug Peptide into Amyloid Fibrils: A Dynamic Circular Dichroism Study. Langmuir 2018, 34 (24), 7180-7191. https://doi.org/10.1021/acs.langmuir.8b00094.

(29) Cremades, N.; Cohen, S. I. A.; Deas, E.; Abramov, A. Y.; Chen, A. Y.; Orte, A.; Sandal, M.; Clarke, R. W.; Dunne, P.; Aprile, F. A.; Bertoncini, C. W.; Wood, N. W.; Knowles, T. P. J.; Dobson, C. M.; Klenerman, D. Direct Observation of the Interconversion of Normal and Toxic Forms of $\alpha$-Synuclein. Cell 2012, 149 (5), 1048-1059. https://doi.org/10.1016/j.cell.2012.03.037.

(30) Carulla, N.; Caddy, G. L.; Hall, D. R.; Zurdo, J.; Gairí, M.; Feliz, M.; Giralt, E.; Robinson, C. V.; Dobson, C. M. Molecular Recycling within Amyloid Fibrils. Nature 2005, 436 (7050), 554-558. https://doi.org/10.1038/nature03986.

(31) MacPhee, C. E.; Dobson, C. M. Chemical Dissection and Reassembly of Amyloid Fibrils Formed by a Peptide Fragment of Transthyretin11Edited by F. E. Cohen. Journal of Molecular Biology 2000, 297 (5), 1203-1215. https://doi.org/10.1006/jmbi.2000.3600.

(32) Tipping, K. W.; Karamanos, T. K.; Jakhria, T.; Iadanza, M. G.; Goodchild, S. C.; Tuma, R.; Ranson, N. A.; Hewitt, E. W.; Radford, S. E. PH-Induced Molecular Shedding Drives the Formation of Amyloid Fibril-Derived Oligomers. Proc Natl Acad Sci USA 2015, 112 (18), 5691-5696. https://doi.org/10.1073/pnas.1423174112.

(33) Valéry, C.; Artzner, F.; Paternostre, M. Peptide Nanotubes: Molecular Organisations, Self-Assembly Mechanisms and Applications. Soft Matter 2011, 7 (20), 9583. https://doi.org/10.1039/c1sm05698k.

(34) Nespovitaya, N.; Gath, J.; Barylyuk, K.; Seuring, C.; Meier, B. H.; Riek, R. Dynamic Assembly and Disassembly of Functional $\beta$-Endorphin Amyloid Fibrils. Journal of the American Chemical Society 2016, 138 (3), 846-856. https://doi.org/10.1021/jacs.5b08694.

(35) Kam, P. C. A.; Williams, S.; Yoong, F. F. Y. Vasopressin and Terlipressin: Pharmacology and Its Clinical Relevance. Anaesthesia 2004, 59 (10), 993-1001. https://doi.org/10.1111/j.1365-2044.2004.03877.x.

(36) Maffucci, I.; Contini, A. In Silico Drug Repurposing for SARS-CoV-2 Main Proteinase and Spike Proteins. J. Proteome Res. 2020, 19 (11), 4637-4648. https://doi.org/10.1021/acs.jproteome.0c00383.

(37) Valéry, C.; Paternostre, M.; Robert, B.; Gulik-Krzywicki, T.; Narayanan, T.; Dedieu, J.C.; Keller, G.; Torres, M.-L.; Cherif-Cheikh, R.; Calvo, P. Biomimetic Organization: Octapeptide Self-Assembly into Nanotubes of Viral Capsid-like Dimension. Proceedings of the National Academy of Sciences 2003, 100 (18), 10258-10262.

(38) Grondelle, W. van; Iglesias, C. L.; Coll, E.; Artzner, F.; Paternostre, M.; Lacombe, F.; Cardus, M.; Martinez, G.; Montes, M.; Cherif-Cheikh, R.; Valéry, C. Spontaneous Fibrillation of the Native Neuropeptide Hormone Somatostatin-14. Journal of Structural Biology 2007, 160 (2), 211-223. https://doi.org/10.1016/j.jsb.2007.08.006.

(39) Anoop, A.; Ranganathan, S.; Dhaked, B. D.; Jha, N. N.; Pratihar, S.; Ghosh, S.; Sahay, S.; Kumar, S.; Das, S.; Kombrabail, M.; Agarwal, K.; Jacob, R. S.; Singru, P.; Bhaumik, P.; Padinhateeri, R.; Kumar, A.; Maji, S. K. Elucidating the Role of Disulfide Bond on Amyloid Formation and Fibril Reversibility of Somatostatin-14 RELEVANCE TO ITS 
STORAGE AND SECRETION. J. Biol. Chem. 2014, 289 (24), 16884-16903. https://doi.org/10.1074/jbc.M114.548354.

(40) Valéry, C.; Deville-Foillard, S.; Lefebvre, C.; Taberner, N.; Legrand, P.; Meneau, F.; Meriadec, C.; Delvaux, C.; Bizien, T.; Kasotakis, E.; Lopez-Iglesias, C.; Gall, A.; Bressanelli, S.; Le Du, M.-H.; Paternostre, M.; Artzner, F. Atomic View of the Histidine Environment Stabilizing Higher-PH Conformations of PH-Dependent Proteins. Nature Communications 2015, 6, 7771. https://doi.org/10.1038/ncomms8771.

(41) Hutchinson, J. A.; Burholt, S.; Hamley, I. W. Peptide Hormones and Lipopeptides: From Self-Assembly to Therapeutic Applications: Peptides: From Self-Assembly to Therapeutic Applications. Journal of Peptide Science 2017. https://doi.org/10.1002/psc.2954.

(42) Morelli, A.; Ertmer, C.; Rehberg, S.; Lange, M.; Orecchioni, A.; Cecchini, V.; Bachetoni, A.; D'Alessandro, M.; Van Aken, H.; Pietropaoli, P. Continuous Terlipressin versus Vasopressin Infusion in Septic Shock (TERLIVAP): A Randomized, Controlled Pilot Study. Crit Care 2009, 13 (4), R130.

(43) Feitelson, J. On the Mechanism of Fluorescence Quenching. Tyrosine and Similar Compounds. The Journal of Physical Chemistry 1964, 68 (2), 391-397.

(44) Ruggeri, F. S.; Adamcik, J.; Jeong, J. S.; Lashuel, H. A.; Mezzenga, R.; Dietler, G. Influence of the $\beta$-Sheet Content on the Mechanical Properties of Aggregates during Amyloid Fibrillization. Angewandte Chemie International Edition 2015, 54 (8), 2462-2466. https://doi.org/10.1002/anie.201409050.

(45) Hernández, B.; Carelli, C.; Coïc, Y.-M.; De Coninck, J.; Ghomi, M. Vibrational Analysis of Amino Acids and Short Peptides in Aqueous Media. V. The Effect of the Disulfide Bridge on the Structural Features of the Peptide Hormone Somatostatin-14. The Journal of Physical Chemistry B 2009, 113 (38), 12796-12803. https://doi.org/10.1021/jp904737v.

(46) Sarroukh, R.; Goormaghtigh, E.; Ruysschaert, J.-M.; Raussens, V. ATR-FTIR: A "Rejuvenated" Tool to Investigate Amyloid Proteins. Biochimica et Biophysica Acta (BBA) - Biomembranes 2013, 1828 (10), 2328-2338. https://doi.org/10.1016/j.bbamem.2013.04.012.

(47) Barth, A.; Zscherp, C. What Vibrations Tell about Proteins. Quarterly Reviews of Biophysics 2002, 35 (4), 369-430. https://doi.org/10.1017/S0033583502003815.

(48) Susi, H.; Byler, D. M. Fourier Transform Infrared Study of Proteins with Parallel $\beta$ Chains. Archives of Biochemistry and Biophysics 1987, 258 (2), 465-469. https://doi.org/10.1016/0003-9861(87)90367-5.

(49) Dong, A.; Huang, P.; Caughey, W. S. Protein Secondary Structures in Water from Second-Derivative Amide I Infrared Spectra. Biochemistry 1990, 29 (13), 3303-3308. https://doi.org/10.1021/bi00465a022.

(50) Jackson, M.; Mantsch, H. H. The Use and Misuse of FTIR Spectroscopy in the Determination of Protein Structure. Critical reviews in biochemistry and molecular biology 1995, 30 (2), 95-120.

(51) Serpell, L. C. Alzheimer's Amyloid Fibrils; Structure and Assembly. Biochimica et Biophysica Acta (BBA) 2000, 1502, 16-30.

(52) Beaucage, G. Approximations Leading to a Unified Exponential/Power-Law Approach to Small-Angle Scattering. J Appl Crystallogr 1995, 28 (6), 717-728.

https://doi.org/10.1107/S0021889895005292.

(53) Beaucage, G. Small-Angle Scattering from Polymeric Mass Fractals of Arbitrary MassFractal Dimension. J Appl Crystallogr 1996, 29 (2), 134-146. https://doi.org/10.1107/S0021889895011605. 
(54) Hammouda, B. Analysis of the Beaucage Model. Journal of Applied Crystallography 2010, 43 (6), 1474-1478.

(55) Nicolai, T.; Pouzot, M.; Durand, D.; Weijers, M.; Visschers, R. W. Iso-Scattering Points during Heat-Induced Aggregation and Gelation of Globular Proteins Indicating MicroPhase Separation. Europhysics Letters (EPL) 2006, 73 (2), 299-305. https://doi.org/10.1209/epl/i2005-10391-8.

(56) Chalal, M.; Ehrburger-Dolle, F.; Morfin, I.; Bley, F.; Aguilar de Armas, M.-R.; López Donaire, M.-L.; San Roman, J.; Bölgen, N.; Pişkin, E.; Ziane, O.; Casalegno, R. SAXS Investigation of the Effect of Temperature on the Multiscale Structure of a Macroporous Poly( N -Isopropylacrylamide) Gel. Macromolecules 2010, 43 (4), 2009-2017. https://doi.org/10.1021/ma902655h.

(57) Baccile, N.; Cuvier, A.-S.; Prévost, S.; Stevens, C. V.; Delbeke, E.; Berton, J.; Soetaert, W.; Van Bogaert, I. N. A.; Roelants, S. Self-Assembly Mechanism of PH-Responsive Glycolipids: Micelles, Fibers, Vesicles, and Bilayers. Langmuir 2016, 32 (42), 1088110894. https://doi.org/10.1021/acs.langmuir.6b02337.

(58) Habraken, W. J. E. M.; Tao, J.; Brylka, L. J.; Friedrich, H.; Bertinetti, L.; Schenk, A. S.; Verch, A.; Dmitrovic, V.; Bomans, P. H. H.; Frederik, P. M.; Laven, J.; van der Schoot, P.; Aichmayer, B.; de With, G.; DeYoreo, J. J.; Sommerdijk, N. A. J. M. Ion-Association Complexes Unite Classical and Non-Classical Theories for the Biomimetic Nucleation of Calcium Phosphate. Nature Communications 2013, 4 (1). https://doi.org/10.1038/ncomms2490.

(59) De Yoreo, J. J.; Gilbert, P. U. P. A.; Sommerdijk, N. A. J. M.; Penn, R. L.; Whitelam, S.; Joester, D.; Zhang, H.; Rimer, J. D.; Navrotsky, A.; Banfield, J. F.; Wallace, A. F.; Michel, F. M.; Meldrum, F. C.; Colfen, H.; Dove, P. M. Crystallization by Particle Attachment in Synthetic, Biogenic, and Geologic Environments. Science 2015, 349 (6247), aaa6760aaa6760. https://doi.org/10.1126/science.aaa6760.

(60) Orci, L.; Ravazzola, M.; Amherdt, M.; Madsen, O.; Perrelet, A.; Vassalli, J. D.; Anderson, R. G. Conversion of Proinsulin to Insulin Occurs Coordinately with Acidification of Maturing Secretory Vesicles. J Cell Biol 1986, 103 (6), 2273-2281. https://doi.org/10.1083/jcb.103.6.2273.

(61) Acar, H.; Srivastava, S.; Chung, E. J.; Schnorenberg, M. R.; Barrett, J. C.; LaBelle, J. L.; Tirrell, M. Self-Assembling Peptide-Based Building Blocks in Medical Applications. Advanced Drug Delivery Reviews 2017, 110-111, 65-79. https://doi.org/10.1016/j.addr.2016.08.006.

(62) Doostmohammadi, M.; Ameri, A.; Mohammadinejad, R.; Dehghannoudeh, N.; Banat, I. M.; Ohadi, M.; Dehghannoudeh, G. Hydrogels For Peptide Hormones Delivery: Therapeutic And Tissue Engineering Applications. Drug Des Devel Ther 2019, 13, 34053418. https://doi.org/10.2147/DDDT.S217211.

(63) Rai, U.; Thrimawithana, T. R.; Dharmadana, D.; Valery, C.; Young, S. A. Release Kinetics of Somatostatin from Self-Assembled Nanostructured Hydrogels. Biopolymers 2017, e23085. https://doi.org/10.1002/bip.23085.

(64) Dharmadana, D.; Reynolds, N. P.; Conn, C. E.; Valéry, C. PH-Dependent Self-Assembly of Human Neuropeptide Hormone GnRH into Functional Amyloid Nanofibrils and Hexagonal Phases. ACS Appl. Bio Mater. 2019, 2 (8), 3601-3606. https://doi.org/10.1021/acsabm.9b00468. 
(65) Kwon, J.-H.; Lee, B.-H.; Lee, J.-J.; Kim, C.-W. Insulin Microcrystal Suspension as a LongActing Formulation for Pulmonary Delivery. European Journal of Pharmaceutical Sciences 2004, 22 (2-3), 107-116. https://doi.org/10.1016/j.ejps.2004.02.007.

(66) Manno, M.; Giacomazza, D.; Newman, J.; Martorana, V.; San Biagio, P. L. Amyloid Gels: Precocious Appearance of Elastic Properties during the Formation of an Insulin Fibrillar Network. Langmuir 2010, 26 (3), 1424-1426. https://doi.org/10.1021/la903340v.

(67) Gobeaux, F.; Porcher, F.; Dattani, R. Reversible Morphological Control of Cholecystokinin Tetrapeptide Amyloid Assemblies as a Function of PH. The Journal of Physical Chemistry B 2017, 121 (14), 3059-3069. https://doi.org/10.1021/acs.jpcb.7b02448.

(68) Jing, W.; Guo, F.; Cheng, L.; Zhang, J.-F.; Qi, J.-S. Arginine Vasopressin Prevents Amyloid $\beta$ Protein-Induced Impairment of Long-Term Potentiation in Rat Hippocampus in Vivo. Neuroscience Letters 2009, 450 (3), 306-310. https://doi.org/10.1016/j.neulet.2008.11.053.

(69) Pan, Y.-F.; Chen, X.-R.; Wu, M.-N.; Ma, C.-G.; Qi, J.-S. Arginine Vasopressin Prevents against A $325-35$-Induced Impairment of Spatial Learning and Memory in Rats. Hormones and Behavior 2010, 57 (4), 448-454. https://doi.org/10.1016/j.yhbeh.2010.01.015.

(70) Pan, Y.-F.; Jia, X.-T.; Wang, X.-H.; Chen, X.-R.; Li, Q.-S.; Gao, X.-P.; Qi, J.-S. Arginine Vasopressin Remolds the Spontaneous Discharges Disturbed by Amyloid $\beta$ Protein in Hippocampal CA1 Region of Rats. Regulatory Peptides 2013, 183, 7-12. https://doi.org/10.1016/j.regpep.2013.03.003.

(71) Caughey, B.; Lansbury, P. T. Protofibrils, Pores, Fibrils, and Neurodegeneration: Separating the Responsible Protein Aggregates from The Innocent Bystanders. Annual Review of Neuroscience 2003, 26 (1), 267-298. https://doi.org/10.1146/annurev.neuro.26.010302.081142.

(72) Giuliani, A.; Jamme, F.; Rouam, V.; Wien, F.; Giorgetta, J.-L.; Lagarde, B.; Chubar, O.; Bac, S.; Yao, I.; Rey, S.; others. DISCO: A Low-Energy Multipurpose Beamline at Synchrotron SOLEIL. Journal of Synchrotron Radiation 2009, 16 (6), 835-841.

(73) Wien, F.; Paternostre, M.; Gobeaux, F.; Artzner, F.; Refregiers, M. Calibration and Quality Assurance Procedures at the Far UV Linear and Circular Dichroism Experimental Station DISCO. Journal of Physics: Conference Series 2013, 425 (12), 122014. https://doi.org/10.1088/1742-6596/425/12/122014.

(74) Lees, J. G.; Smith, B. R.; Wien, F.; Miles, A. J.; Wallace, B. A. CDtool-an Integrated Software Package for Circular Dichroism Spectroscopic Data Processing, Analysis, and Archiving. Analytical Biochemistry 2004, 332 (2), 285-289. https://doi.org/10.1016/j.ab.2004.06.002.

(75) Zemb, Th.; Taché, O.; Né, F.; Spalla, O. Improving Sensitivity of a Small Angle X-Ray Scattering Camera with Pinhole Collimation Using Separated Optical Elements. Review of Scientific Instruments 2003, 74 (4), 2456-2462. https://doi.org/10.1063/1.1556954. 